Revue des patrimoines

\title{
Modernisations industrielles et fabrications traditionnelles dans la Grande Guerre à travers la photographie et le cinéma militaires
}

Véronique Goloubinoff

\section{(2) OpenEdition}

Journals

Édition électronique

URL : http://journals.openedition.org/insitu/10924

DOI : 10.4000/insitu.10924

ISSN : 1630-7305

Éditeur

Ministère de la Culture

\section{Référence électronique}

Véronique Goloubinoff, " Modernisations industrielles et fabrications traditionnelles dans la Grande Guerre à travers la photographie et le cinéma militaires », In Situ [En ligne], 23 | 2014, mis en ligne le 28 février 2014, consulté le 10 décembre 2020. URL : http://journals.openedition.org/insitu/10924 ; DOI : https://doi.org/10.4000/insitu.10924

Ce document a été généré automatiquement le 10 décembre 2020.

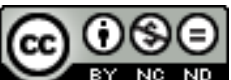

In Situ Revues des patrimoines est mis à disposition selon les termes de la licence Creative Commons Attribution - Pas d'Utilisation Commerciale - Pas de Modification 4.0 International. 


\title{
Modernisations industrielles et fabrications traditionnelles dans la Grande Guerre à travers la photographie et le cinéma militaires
}

\author{
Véronique Goloubinoff
}

À l'automne 1914, à la fin de la guerre de mouvement et de la «course à la mer ", neuf départements français du Nord et de l'Est sont partiellement occupés et celui des Ardennes l'est entièrement. Deux millions de Français se retrouvent sous la domination de l'ennemi. Certains secteurs ne sont que brièvement investis mais d'autres vont le rester pendant presque tout le conflit. La richesse agricole et surtout industrielle de ces territoires passe sous contrôle allemand. Dans le Nord, région manufacturière la plus puissante du pays avec la région parisienne, les mines, la sidérurgie et le textile sont mis au service de l'occupant, les machines parfois démontées et emportées en Allemagne ainsi que les matières premières; ce qui n'est pas transportable est détruit sur place lorsque l'ennemi se retire. En trois mois, la France perd ses bassins houillers du Nord, qui représentent $74 \%$ de la production nationale (fig. $\mathbf{n}^{\circ} \mathbf{1}$ ) et ses gisements de fer de Lorraine. Elle perd $63 \%$ de sa production d'acier, $81 \%$ de sa production de fonte et plus de $90 \%$ de sa capacité à produire du laiton, alliage de cuivre indispensable à la fabrication des douilles d'obus. Le rail se trouve subitement dévolu au transport des soldats, au détriment des matières premières dont le déficit est accentué par le blocus. Les importations en provenance d'Allemagne cessent, notamment celle du charbon - la France n'en produit qu'à hauteur de $65 \%$ de ses besoins - mais aussi celle du benzol, nécessaire à la fabrication de la mélinite (ou acide picrique, utilisé comme explosif). Sur le front, la pénurie de projectiles et d'explosifs, dont la consommation dépasse toutes les prévisions, ne tarde pas à se faire sentir. La hiérarchie militaire n'a pas prévu une guerre longue et doit improviser dans l'urgence pour continuer à approvisionner les batteries et bientôt remplacer les matériels détruits mais aussi vêtir, nourrir et équiper les troupes désormais immobilisées dans les tranchées. Les photographies et les films réalisés par les Sections photographique et cinématographique de l'armée, fusionnées en 1917 en une 
seule entité, la Section photographique et cinématographique de l'armée (SPCA), permettent de suivre l'évolution de la production et du tissu industriel en France pendant toute la guerre ${ }^{1}$.

Figure 1

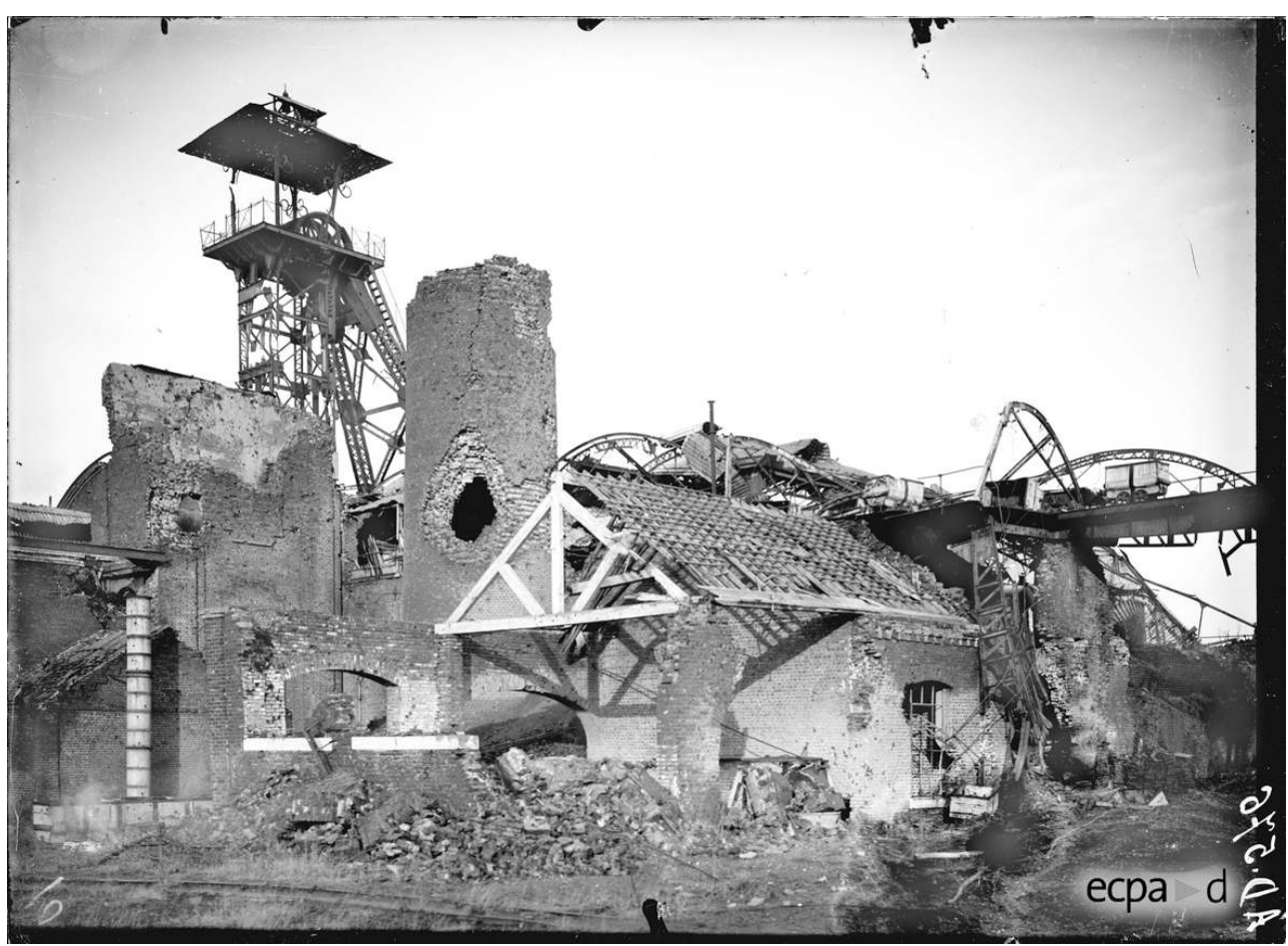

LIÉVIN (PAS-DE-CALAIS). ENSEMBLE DE LA PARTIE OUEST dE LA MINE.

PHOT. DANIAU. (C) ECPAD, 1919, RÉF. SPA 20 AD 576.

\section{Des canons ! Des munitions !}

Depuis 1907, le sénateur de la Meuse Charles Humbert, ancien officier d'ordonnance d'un ministre de la Guerre, converti au journalisme, ne cesse de plaider pour l'accroissement des moyens matériels de l'armée. Ce slogan revient inlassablement dans les articles et pamphlets qu'il publie dans la presse et ses interpellations devant le Sénat où il dénonce l'impréparation militaire de la France dans un éventuel conflit avec l'Allemagne ${ }^{2}$. Le plan de mobilisation de 1913 prévoit le maintien de 50000 ouvriers dans une trentaine d'usines afin de maintenir partiellement la production mais n'envisage pas de lancer de nouvelles fabrications. Or, dès le début de septembre 1914, la croissance des besoins en obus et poudres s'avère exponentielle et l'approvisionnement ne peut pas suivre la cadence des tirs. Le 19 septembre, alors que la consommation quotidienne est de 700 coups pour les pièces de gros calibre, il n'en reste que 150 dans les dépôts ${ }^{3}$. Le général Joffre voudrait que l'artillerie soit approvisionnée à 100000 coups par jour mais les arsenaux nationaux, incapables de répondre à une telle demande, ne peuvent en fournir que 13000 . Face à cette situation de crise, le cas de la région parisienne est emblématique de la façon dont l'État, les industriels et l'autorité militaire vont s'organiser pour redéployer vers des fabrications de guerre l'outil de production existant et pour l'adapter à l'exigence de nouveaux matériels. 


\section{La région parisienne : un réseau dynamique au service d'industries de pointe}

Depuis un siècle, l'industrie prospère en région parisienne. Comme le souligne François Caron, « c'est à Paris que les nouveaux secteurs d'activité apparaissent et connaissent leur premier essor ; puis, dans un second temps, ils se décentralisent en province. L'économie industrielle parisienne connaît ainsi un processus de perpétuel renouvellement ${ }^{4}{ }$. Après le choc de 1870 et la crise économique des années 1880, le tissu industriel parisien s'est reconstruit et reconverti. En 1914, la construction mécanique est prospère : l'automobile, l'aéronautique et le secteur électrique sont en plein développement, s'appuyant sur un réseau de sous-traitants très fourni, petits ateliers répartis entre la capitale et la banlieue où l'espace et le moindre coût du terrain ont favorisé l'implantation d'usines mettant en œuvre des méthodes de production rationnelles. L'industrie de pointe coexiste avec un artisanat parisien très créateur, bien que le centre de la capitale ait déjà tendance à se désindustrialiser. Les petits ateliers, qui ont d'abord souffert de l'apparition des machines-outils, se sont reconvertis dans la fabrication de pièces de précision et de pièces détachées d'une part, dans celle des instruments de précision et de mesure d'autre part. La main-d'œuvre est abondante et s'est vue renforcée par l'arrivée d'immigrés italiens à la fin du XIX ${ }^{e}$ siècle. Le vivier des ingénieurs est alimenté par un dispositif de formation performant: aux deux "anciennes ", l'École polytechnique et l'École centrale, se sont ajoutées l'École municipale de physique et de chimie, l'École d'application du laboratoire central d'électricité (qui deviendra Supelec) et de nombreuses écoles techniques privées (école Violet et école Bréguet notamment) qui assurent tout un éventail de qualifications cadrant avec la variété de secteurs manufacturiers en pleine croissance. Tout cet appareil est aux mains d'un patronat dynamique, d'origine locale ou provinciale, voire étrangère, issu de grandes dynasties industrielles ou bien constitué de nouveaux arrivants qui proviennent de milieux techniques et scientifiques, ou des classes moyennes et populaires, ou même du milieu sportif (Henri Farman est un pilote automobile). Ces chefs d'entreprise ont développé des réseaux de relations interprofessionnelles «au sein desquelles circulent les hommes, les capitaux, les connaissances et les informations ${ }^{5}$ " dans un mode de fonctionnement interactif. L'effort de recherche est souvent mutualisé et favorisé en aval par les banques. Le développement s'est accompagné d'un début de migration de l'outil de production vers la banlieue, qui offre davantage d'espace, où de vastes bâtiments modernes à structure métallique (fig. $\left.\mathbf{n}^{\circ} \mathbf{2}\right)$ prennent le relais des ateliers parisiens, dont certains seront d'ailleurs détruits pendant les bombardements de 1918 . Ces synergies confèrent à l'industrie de la région parisienne une grande modernité, tant du point de vue de ses équipements que de leur mise en œuvre. 
Figure 2

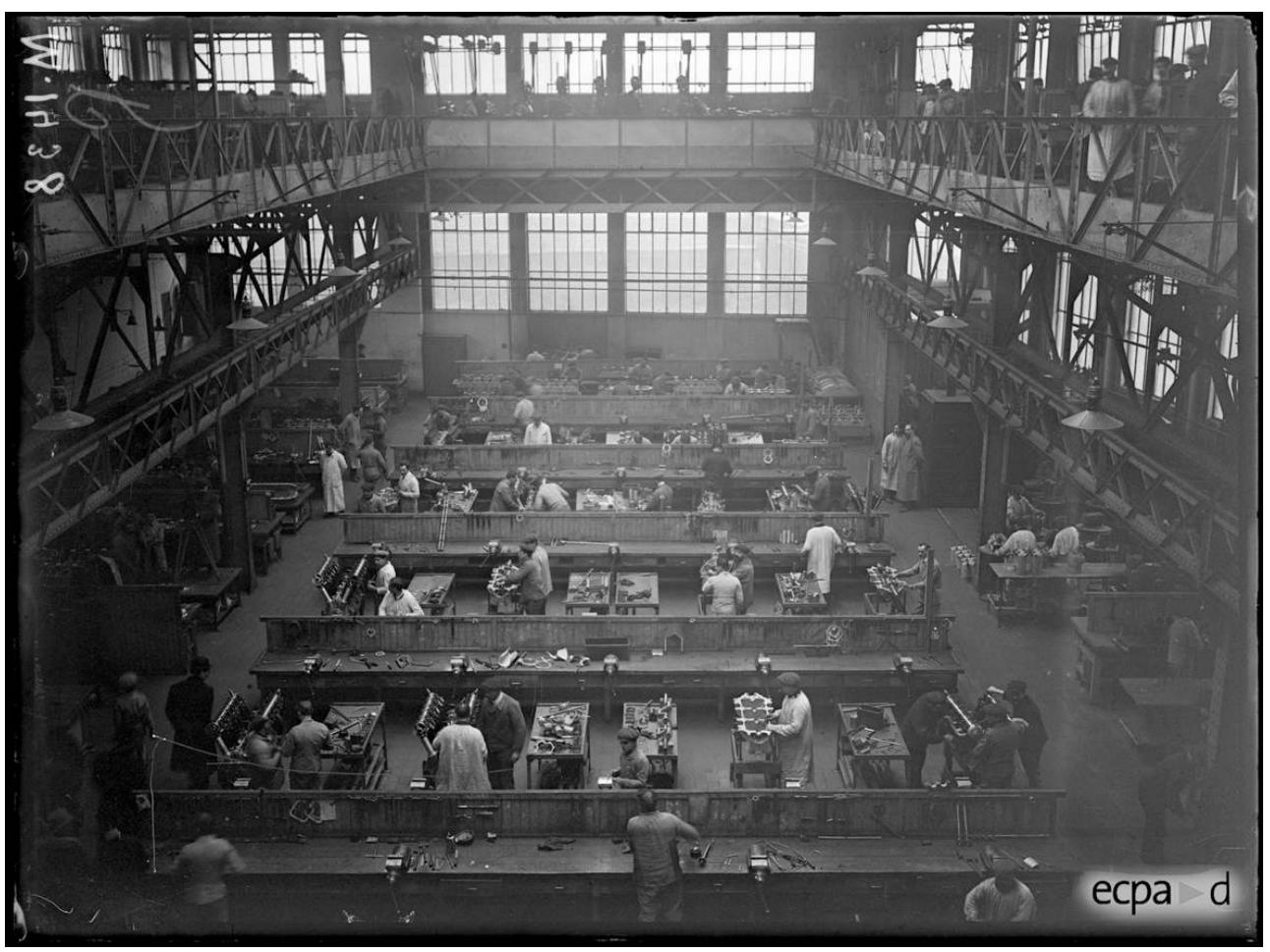

Les ATELIERS RENAULt AUX USiNes de BILLANCOURT (HAUTS-DE-SEINE).

PHOT. MOREAU, ALBERT. (C) ECPAD, JANVIER 1916, RÉF. SPA 60 M 1438.

4 C'est la richesse et l'interopérabilité de ce tissu industriel qui vont permettre de faire face, dans la douleur et au détriment des fabrications civiles, aux défis d'une production de guerre qui est loin d'être sa spécialité.

5 Rémy Porte ${ }^{6}$ distingue trois périodes dans l'adaptation de l'industrie française : à une première phase d'hésitations et d'improvisations, de 1914 au printemps 1915, succède en 1915 et 1916 une période d'initiatives et de développement au cours de laquelle l'appareil productif acquiert progressivement de l'expérience; en décembre 1916, Albert Thomas (fig. $\mathbf{n}^{\circ} \mathbf{3}$ ), un socialiste jusqu'ici sous-secrétaire d'État à l'Artillerie, est nommé ministre de l'Armement de plein exercice, avec comme second Louis Loucheur qui le remplace à l'Artillerie ; commence alors une phase de planification et de rationalisation au cours de laquelle le ministre reprend la main sur une organisation laissée jusque-là en grande partie aux mains du patronat. Elle portera pleinement ses fruits en 1918. Dans une étude sur la guerre de 1914-1918 et l'industrie mécanique en région parisienne, Toshikatsu Nakajima $^{7}$ distingue lui aussi dans cette reconversion industrielle trois phases successives qui recoupent chronologiquement et en partie celles que mentionne Rémy Porte: de septembre 1914 au printemps 1915, tout l'effort de la région se porte, dans la hâte, sur la fabrication d'obus ; de 1915 au printemps 1917, l'industrie privée parisienne commence à fournir des canons et des fusils qui complètent la production des arsenaux ; à partir de 1917, l'accent est mis de plus en plus sur la construction de véhicules militaires et d'avions, ce dernier secteur étant toutefois déjà très actif avant le conflit. 


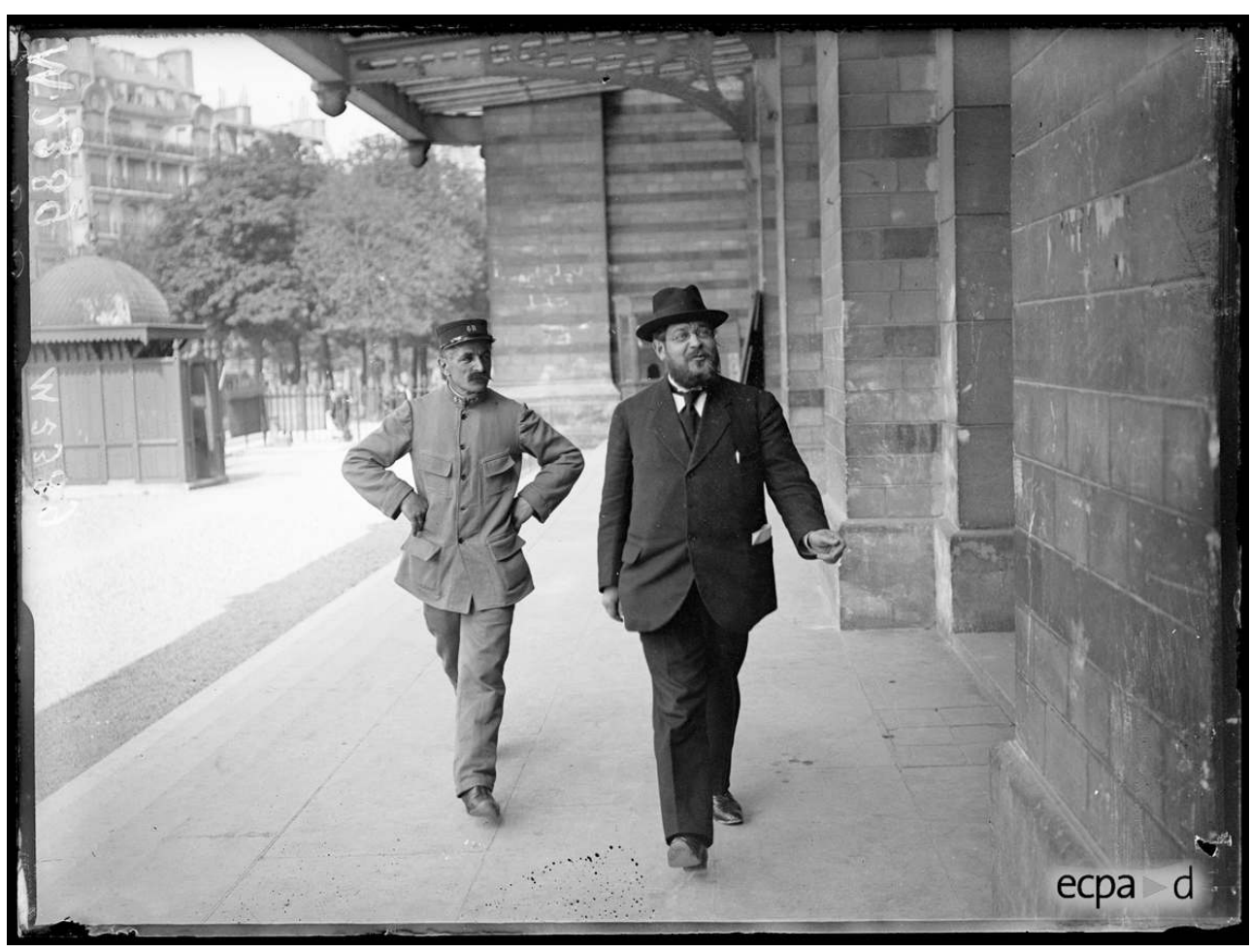

ALBERT THOMAS ARRIVE AU TROCADÉRO POUR LA MANIFESTATION EN HOMMAgE À JEAN JAURÈS. PHOT. MOREAU, ALBERT. ㄷ ECPAD, JANVIER 1916, RÉF. SPA 113 M 2389.

6 À la différence de ce qui se pratique en Allemagne, où les entreprises sont réquisitionnées, le gouvernement français, plutôt que d'agir de façon coercitive, va travailler en concertation avec elles afin de bénéficier au mieux de leurs compétences techniques. Un discours d'Albert Thomas prononcé devant les industriels le 28 août 1915 résume cet état d'esprit :

Le gouvernement aura le devoir de régler et d'organiser la production. Si un jour il est obligé de répartir les commandes selon l'ordre d'urgence ou de répartir la maind'œuvre selon les nécessités, il devra imposer aux industriels quelques obligations lourdes. Mais il sait que ce n'est pas en vain qu'il fera appel à leur dévouement envers la patrie et qu'il n'aura pas besoin de recourir à des mesures d'autorité.

7 Un an plus tard, le système semble fonctionner si l'on en juge les propos de ce même ministre aux usines du Creusot :

Hier, pendant la paix, les industriels multipliaient les reproches à l'égard de l'État. Aujourd'hui, ils ont discipliné leurs efforts, ils ont répondu à l'appel de la nation, ils ont permis cette organisation d'ensemble que les plus audacieux d'entre nous n'avaient pas osé rêver. Il s'est formé dans l'industrie comme une organisation supérieure d'État qui a su coordonner toutes les initiatives, sans en étouffer aucune.

Il est vrai que les chefs d'entreprise y trouvent aussi leur compte : Renault, par exemple, va presque multiplier par quatre son chiffre d'affaires pendant la guerre.

\section{4-1915, année des obus}

9 Le 20 septembre 1914, le député de la Seine Alexandre Millerand décide de créer sept groupes régionaux d'industriels chapeautés par de grandes entreprises, chargés de 
mobiliser l'industrie privée. À Paris, Louis Renault coordonne un ensemble de douze sociétés et un syndicat ${ }^{8}$. Il reçoit les commandes et les répartit entre les membres du groupe. La plupart des ateliers de mécanique sont alors à l'arrêt en raison de la mobilisation mais, dans l'urgence, le ministère de la Guerre autorise le retour d'un certain nombre d'ouvriers. Ultérieurement, pour ne pas dégarnir le front, le gouvernement organisera mieux le retour de la main-d'œuvre en créant trois catégories ${ }^{9}$ : les ouvriers spécialistes, qui travaillaient dans leur secteur avant le conflit; les ouvriers "spécialisés ", qui ont fait leurs preuves depuis leur retour du front; les ouvriers non spécialisés. Seules les deux premières catégories peuvent rester dans les usines, les hommes relevant de la troisième devant regagner la zone des combats. Avec le retour d'un premier contingent d'hommes, la construction mécanique peut redémarrer. Il faut produire d'urgence des quantités d'obus. Toutefois, une telle opération ne peut s'improviser.

La réalisation d'un obus comporte six phases (ou sept suivant les constructeurs) dont la première, la mise en forme du contenant à partir d'une section de barre de métal, est la plus problématique. Avant guerre, elle se fait par emboutissage à la presse hydraulique dans les arsenaux d'État, qui détiennent le monopole de la fabrication. Après remplissage (billes métalliques ou produits fusants, percuteur, etc.), la tête est sertie à chaud puis l'ensemble subit des opérations de finition (trempage, recuit, ceinturage). Cependant, les presses utilisées par les arsenaux sont à l'époque peu répandues dans le privé. En effet, dans l'industrie automobile naissante, les carrosseries sont faites de tôles plates découpées, de toile et de bois. Les constructeurs sont en revanche largement équipés de tours et c'est pourquoi l'idée germe de fabriquer les obus par décolletage ${ }^{10}$, c'est-à-dire en $^{\prime}$ forant une barre d'acier pour creuser la cavité intérieure à l'aide d'une première machine (fig. $\left.\mathbf{n}^{\circ} 4\right)$ puis en effectuant la finition extérieure avec un deuxième tour ${ }^{11}$. La tête est ensuite vissée après remplissage (d'où le nom de «bibloc» donné à ces projectiles). Cependant, le forage au tour, plus lent, laisse aussi une quantité de déchets métalliques et consomme trop de matières premières; en outre, l'acier rapide des outils, soumis à une très forte cadence de travail, atteint ses limites de résistance. Les usines devront ultérieurement s'équiper en presses pour passer à l'emboutissage, plus économique, et le travail au tour sera progressivement abandonné. Lorsque les arsenaux seront à même de fournir les quantités nécessaires d'obus, les industriels se tourneront alors vers d'autres fabrications de guerre, et ceci d'autant plus que le prix d'achat de l'obus par l'armée aura baissé. 
Figure 4

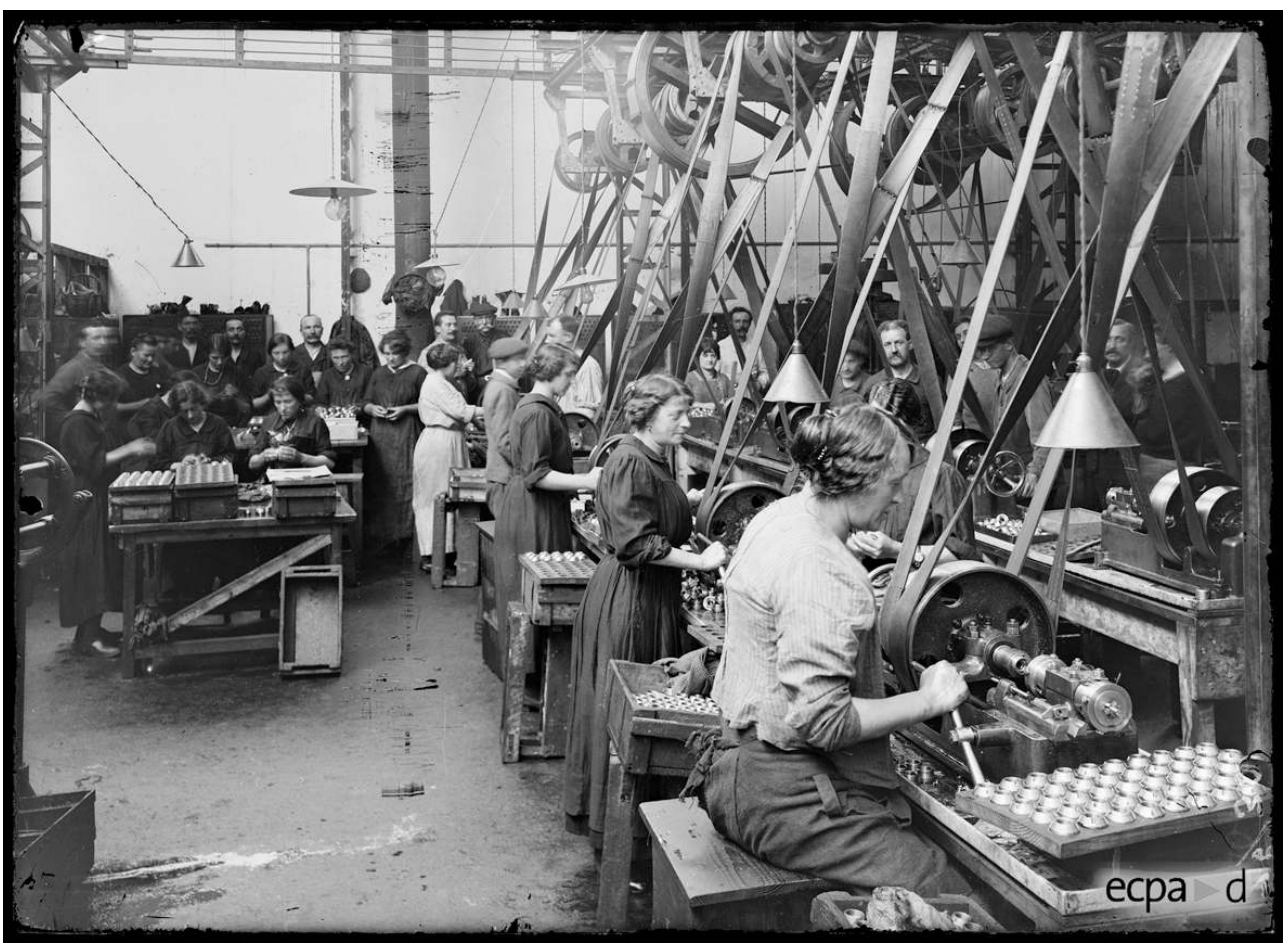

SOCIÉTÉ d'ÉcLAIRAgE ÉLECTRIQUE de SURESNES (HAUTS-DE-SEINE). ATELIER DES gAINES. CONTRÔLE ET MACHINES À TARAUDER.

PHOT. AUBERT, ISIDORE. (C) ECPAD, JUILLET 1915, RÉF. SPA 3 Z 5-30.

L'usinage d'obus commence chez les constructeurs automobiles dès l'automne 1914, notamment à Billancourt, chez Renault, où la structure de la production va progressivement évoluer des fabrications spécifiques vers la production militaire :

\begin{tabular}{|l|l|l|}
\hline Production annuelle des usines Renault & $\mathbf{1 9 1 4}$ & $\mathbf{1 9 1 8}$ \\
\hline Voitures & 1484 & 553 \\
\hline Camions & 174 & 1793 \\
\hline Chars d'assaut & 0 & 750 \\
\hline Moteurs d'avions & 0 & 5000 \\
\hline Obus de 75 et 155 mm & 0 & 2000000 \\
\hline Surface des usines & $11,5 \mathrm{ha}$ & $34 \mathrm{ha}$ \\
\hline $\begin{array}{l}\text { Effectifs } \\
\text { Dont femmes }\end{array}$ & 6300 & 22500 \\
\hline
\end{tabular}

D’après R. Fridenson, Histoire des usines Renault. Paris : Le Seuil, 1972. 
La plupart des usines produisent des obus explosifs, plus simples à fabriquer que les obus à balles (shrapnells). Toutefois, Citroën se lance dans cette fabrication complexe au sein de son établissement du quai de Javel, en achetant des presses hydrauliques et des machines-outils. La première partie d'un film, tourné probablement en janvier $1917^{12}$, montre les opérations successives de la production: tronçonnage des barres d'acier, chauffage, emboutissage sur une quinzaine de presses qui semblent d'origine américaine, usinage par un personnel essentiellement féminin, trempage, ceinturage, forgeage et taraudage des ogives, suivis du contrôle de la qualité. Vient ensuite la confection des billes de shrapnell: les lingots de plomb sont tréfilés sur une étireuse de marque $\mathrm{J}$. Robertson (fig. $\mathbf{n}^{\circ}$ ), importée de Brooklyn, puis découpés en billes qui vont remplir les obus sur lesquels on soude les ogives. Les autres constructeurs automobiles hésitent à investir dans des installations aussi coûteuses, qui ne serviront pas forcément après la guerre, et préfèrent disperser la production chez les sous-traitants. Cependant, totalement requis par les productions de guerre, ils sont tout de même obligés de mettre de côté leurs fabrications habituelles et les innovations techniques qui s'y rapportent, les repoussant à une période postérieure au conflit.

Figure 5

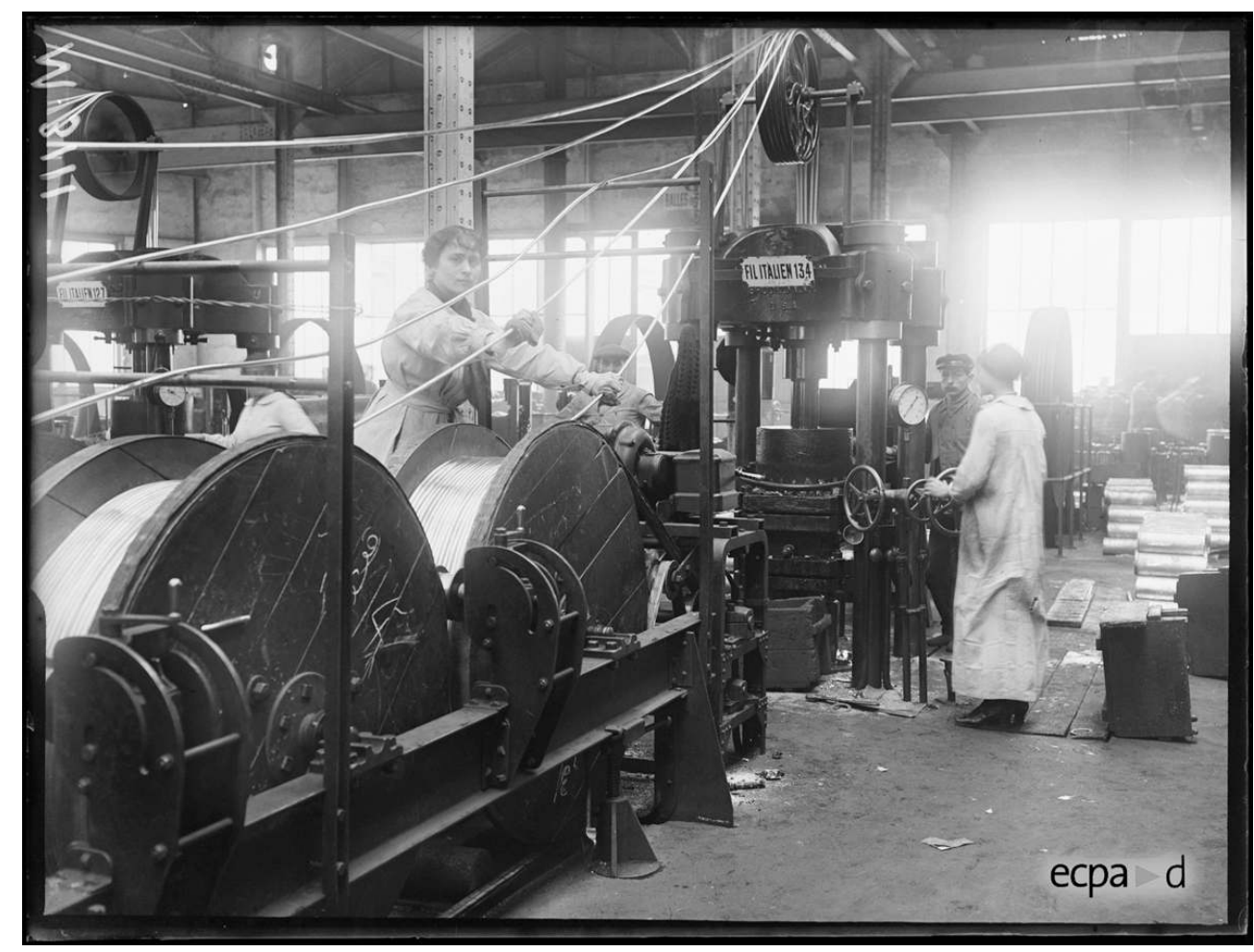

USines CITROËn dU QUAI de JAVEL. APRÈs L'ÉtiRAge, Les fils de PLOMB S'ENROULENT SUR de gROSSES BOBINES.

PHOT. MOREAU, ALBERT. (C) ECPAD, JANVIER 1916, RÉF. SPA 153 M 3111.

Rapidement, les grands établissements croulent sous les commandes de l'État et font alors jouer les ramifications les plus profondes de leurs réseaux de sous-traitants. Toshikatsu Nakajima cite l'exemple d'un imprimeur de Levallois dont le fils, dans une annexe de l'entreprise de son père, fabrique des ébauches d'obus pour la maison otto (XVe arrondissement), elle-même sous-traitante de Schneider. De même, la production de douilles se répand dans une multitude d'établissements, certains des plus inattendus 
comme l'orfèvre Christofle par exemple. La division du travail au sein de cet entrelacs d'entreprises et d'ateliers consomme beaucoup de main-d'œuvre et les ouvriers rapatriés du front, qui ont récupéré leur statut civil et leur salaire, ne suffisent plus. Dans un rapport présenté à la commission sénatoriale de l'armée le 7 juillet 1915, le sénateur Charles Humbert dénonce la difficulté qu'éprouvent les industriels à se procurer de la main-d'œuvre et énumère une longue liste d'installations qui sont à l'arrêt dans les usines, notamment 50 tours inutilisés chez Delaunay-Belleville, faute de personnel ${ }^{13}$. On recourt alors aux travailleurs en provenance de l'étranger et des colonies (Afrique du Nord, Chine, Indochine), ainsi qu'aux hommes non mobilisables, aux jeunes et aux femmes. À la fin de 1915, celles que le président du Conseil René Viviani avait d'abord exhortées à remplacer les hommes dans les activités agricoles renforcent leur présence dans les usines. D'octobre 1915 à octobre 1916, le nombre de femmes travaillant pour la défense nationale passe de 55800 (13,4\% de l'effectif total) à 314255 (23,3\%). Pour le seul secteur de la marine, la proportion atteint même $33,4 \%$ en octobre $1916^{14}$. Occupées auparavant à d'autres tâches (travail domestique, textile, vente), elles expérimentent des métiers plus physiques et se retrouvent à utiliser des tours, des colonnes de perçage, des presses, des ponts-roulants ou à conduire des chariots électriques et même à faire de la soudure au chalumeau. Certaines manipulent quotidiennement des milliers d'obus (fig. $\mathbf{n}$ '6) comme en témoigne Marcelle Capy, une journaliste embauchée incognito dans un atelier, où elle observe une contrôleuse à son poste, occupée à une tâche répétitive :

L'ouvrière, toujours debout, saisit l'obus, le porte sur l'appareil dont elle soulève la partie supérieure. L'engin en place, elle abaisse cette partie, vérifie les dimensions (c'est le but de l'opération), relève la cloche, prend l'obus et le dépose à gauche. Chaque obus pèse sept kilos. En temps de production normale, 2500 obus passent en 11 heures entre ses mains. Comme elle doit soulever deux fois chaque engin, elle soupèse en un jour $35000 \mathrm{~kg}^{15}$.

En Allemagne par contre, les femmes ne sont pas autant impliquées dans l'effort de guerre qu'en France. En effet, la loi sur le travail auxiliaire votée par le Reichstag le 5 décembre 1916 mobilise les hommes de 17 à 60 ans mais une loi spéciale qui mobiliserait la main-d'œuvre féminine ne voit jamais le jour, face au conservatisme social ${ }^{16}$. 


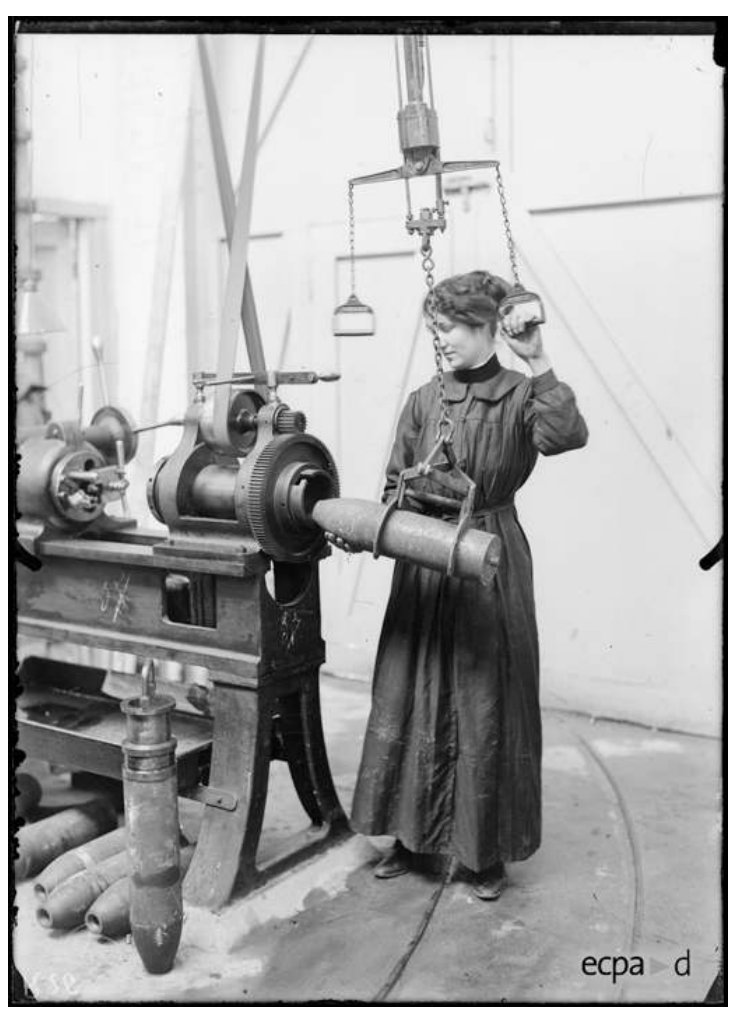

USINE VedOVELL, PRIESTLEY et CIE (ATELIERS DE CONSTRUCTION ÉleCtRIQUE, 160 RUE SAINTCHARLES, PARIS). VÉRIFICATION DU VOLUME INTÉRIEUR DES OBUS.

PHOT. RIBAR. () ECPAD, JANVIER 1916, RÉF. SPA 3 R 26.

Les adolescents contribuent aussi à l'effort industriel. Au début de la guerre, l'entrée dans la vie active, régie par une loi de 1892, est autorisée à partir de 13 ans, pour une durée maximale de 10 heures par jour jusqu'à 16 ans, et pour une durée de 11 heures entre 16 ans et 18 ans. Un décret du 21 mars 1914 liste les travaux dangereux interdits aux jeunes de moins de 18 ans et aux femmes. Il proscrit notamment le nettoyage de machines en marche et le travail dans des ateliers où les parties dangereuses ne sont pas couvertes, et réglemente le port de charges lourdes, qui ne peuvent excéder la moitié de ce que peut porter un homme adulte. Sous la pression des industriels, les diverses mesures réglementant l'emploi des jeunes sont assouplies. Sur les clichés pris par les photographes de l'armée, il n'est pas rare de voir de très jeunes garçons au travail (fig. $\mathbf{n}^{\circ}$ 7). Cette levée des restrictions a pour conséquence une augmentation des accidents du travail, relevée dans le Bulletin des usines de guerre du 19 juin 1916. Ils touchent davantage les nouvelles catégories de personnels encore peu expérimentés que sont les femmes, les enfants et les travailleurs étrangers ou coloniaux. Chez Michelin par exemple, à Clermont-Ferrand, les étrangers et coloniaux, qui constituent $14 \%$ de l'effectif, représentent $28 \%$ des accidentés du travail. Toujours en Auvergne, on cite le cas d'un enfant de 14 ans, plutôt frêle, victime d'une grave hernie après avoir porté des charges de $15 \mathrm{~kg} 12$ heures par jour, en infraction à la législation ${ }^{17}$. À la fin de la guerre, l'industrie de l'armement emploie 430000 femmes, 922000 ouvriers dont plus de la moitié sont militaires, 133000 enfants de moins de 18 ans, 13000 mutilés, 108000 étrangers, 61000 travailleurs coloniaux et 40000 prisonniers $^{18}$. 
Figure 7

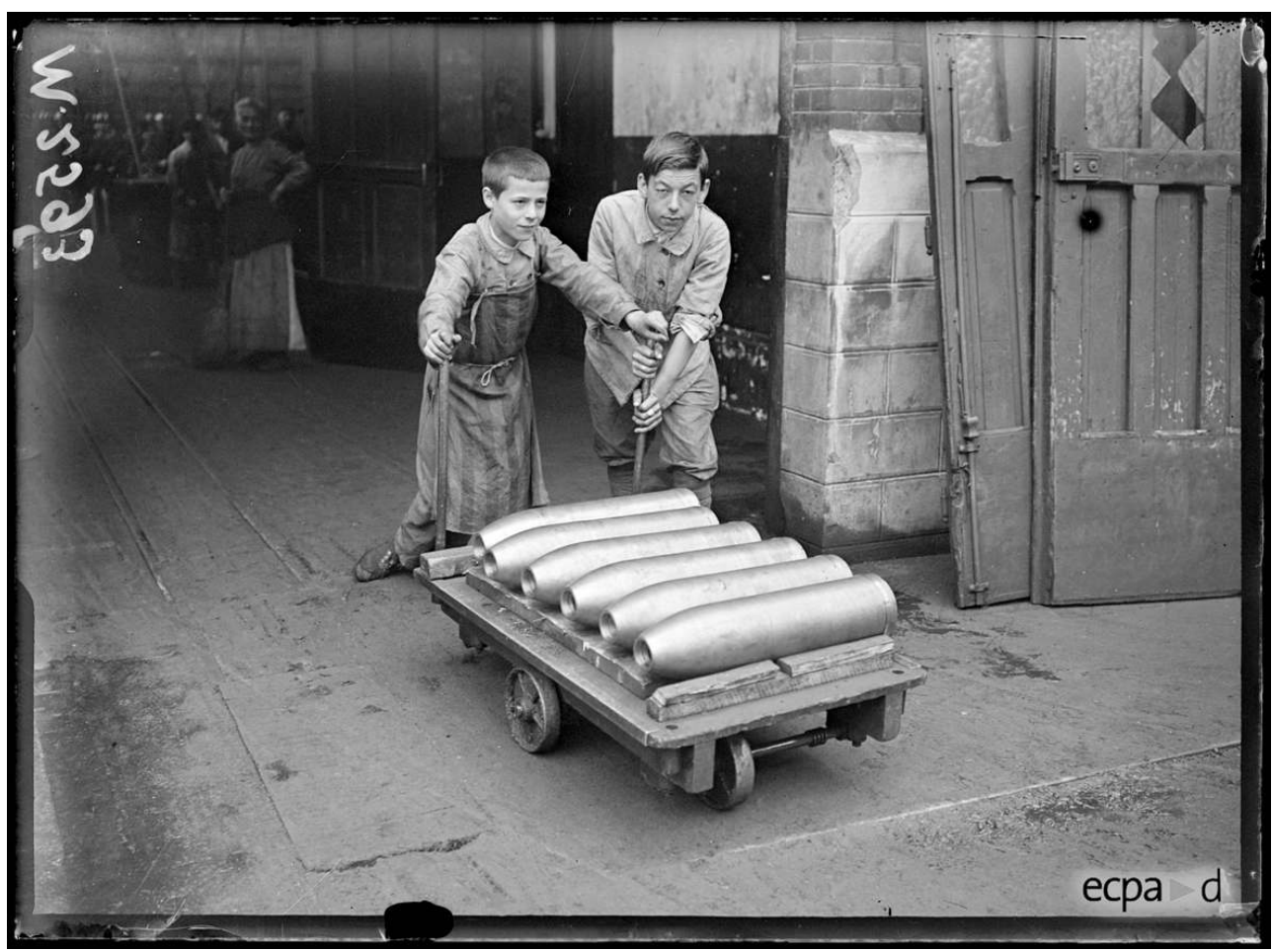

USINE CLÉMENT-BAYARD, LEVALLOIS-PERRET (HAUTS-DE-SEINE). ENFANTS POUSSANT UN CHARIOT CHARgÉ D'OBUS.

PHOT. MOREAU, ALBERT. @ ECPAD, AOÛT 1916, RÉF. SPA 121 M 2593.

17 Mis à part les obus de $75 \mathrm{~mm}$ ou de plus gros diamètre, l'industrie de la région parisienne produit aussi une grande quantité de munitions de petit calibre pour l'infanterie, occupant une nombreuse main-d'œuvre féminine.

Les témoignages apportés par les Sections photographique et cinématographique de l'armée sur l'industrie et l'artisanat dans la région parisienne pendant la guerre sont nombreux: dix-neuf photographes réalisent une soixantaine de reportages, soit pour rendre compte des fabrications proprement dites, soit pour accompagner des personnalités - ministres, commissions diverses, délégations étrangères - en visite. Leur travail représente environ 700 clichés pris dans la capitale et en banlieue. Les photographes Albert Moreau et Paul Lemare sont particulièrement productifs mais on peut également citer Ernest Baguet, Paul Bressolles et Pierre Pansier. Ils sont accompagnés de caméramans qui témoignent des mêmes scènes ${ }^{19}$. Les reportages de l'année 1915 portent surtout sur la fabrication des cartouches et des obus de $75 \mathrm{~mm}$ dans les entreprises privées (usines Renault à Billancourt, Société électrique de Suresnes, usine Vedovelli à Vitry-sur-Seine) et sur celle des obus chimiques dans les installations militaires de "La Craponnière ", à Vincennes, qui semble très " artisanale ». Ils traitent également du secteur agroalimentaire à vocation civile et militaire : moulins de Javel avec leurs machines à bluter et diviseuses à gruaux, laiterie de la rue Legendre avec ses appareils de stérilisation et étable militaire de Levallois. 


\section{5-1916, année des fusils et des canons}

19 En février 1915 débute la production en grande série d'une nouvelle arme, le fusil modèle 07/15 dérivé du fusil Colonial modèle 1907 et destiné à remplacer le Lebel modèle 1886-93. L'armée disposant au début du conflit d'un très important stock de fusils Lebel, suffisant pour équiper toute l'infanterie, la transition d'une arme à l'autre peut se faire en douceur. Mais sur les 2,8 millions de fusils en service en août 1914, le quart est déjà perdu ${ }^{20}$ et il convient de hâter leur remplacement. L'essentiel de la fabrication a lieu dans les manufactures d'État de Châtellerault, Tulle et Saint-Étienne, avec une production globale de plus de deux millions de pièces. Comme l'explique Rémy Porte ${ }^{21}$, cette arme comporte soixante-sept pièces détachées constituant cinq sous-ensembles et nécessite une grande variété de machines de précision et d'outils spécifiques complexes. La production est donc émiettée entre un grand nombre de sociétés sous-traitantes. Toutefois, un constructeur automobile installé à Saint-Ouen, Delaunay-Belleville, effectue les investissements nécessaires et se lance dans la fabrication intégrée de la nouvelle arme, dont il produit 170000 exemplaires au cours de la guerre. Delaunay-Belleville produit également des mortiers de tranchée de 75 et de $150 \mathrm{~mm}$. Quant à Renault, l'entreprise produit dans ses ateliers de Billancourt la majeure partie des pièces du canon de $155 \mathrm{~mm}$ à grande puissance Filloux, assemblées ensuite à Puteaux avec le tube, qui est fabriqué à Bourges. Le constructeur produira ultérieurement le tracteur d'artillerie Renault EG1 à quatre roues motrices, destiné à véhiculer ce même canon (fig. nº).

Figure 8

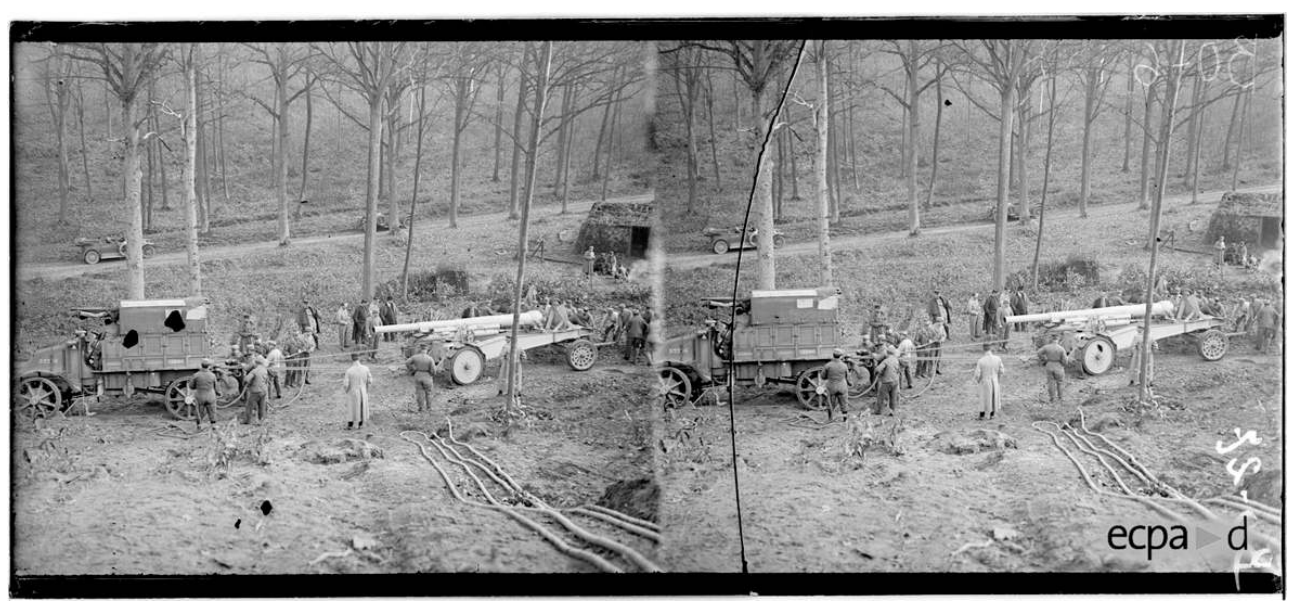

BOIS DE SAINT-CuCUFA (HAUTS-DE-SEINE). ESSAI DE TRACTION D'UN CANON DE 155 MM À gRANDE PUISSANCE PAR UN TRACTEUR RENAULT EG.

PHOT. BOULAY, MAURICE. (C) ECPAD, NOVEMBRE 1916, RÉF. SPA 2 Bo 27.

En 1915, la création de la direction des Inventions intéressant la Défense nationale ${ }^{22}$ et du service cinématographique spécialisé qui s'y rattache va donner lieu à une nouvelle manière de fixer sur pellicule l'armement de cette époque, non plus sous l'angle de la production industrielle mais sous son aspect scientifique et technique. Le service de Cinématographie technique (SCT), qui a des opérateurs en commun avec la Section cinématographique de l'armée (SCA), réalise sur divers modèles de fusils des prises de vues en gros plan et en éclaté, où l'on voit au ralenti le cheminement du projectile dans l'arme, ainsi que des films d'instruction qui montrent en détail le démontage méticuleux 
des fusils et mitrailleuses et leur entretien (fig. $\mathbf{n}^{\circ} \mathbf{9}$ ). L'usage des plans rapprochés permet aussi d'expliquer le fonctionnement des systèmes de réglage de l'artillerie lourde (fig. $\mathbf{n}^{\circ}$ 10). D'autres films d'instruction portent sur la posture pendant le tir au fusil ou au pistolet. D'autres encore expliquent à l'aide de petits dispositifs animés composés de modèles réduits, poulies et cordelettes, les mécanismes physiques à mettre en œuvre pour mouvoir des pièces d'artillerie lourde sur un plan incliné.

Figure 9

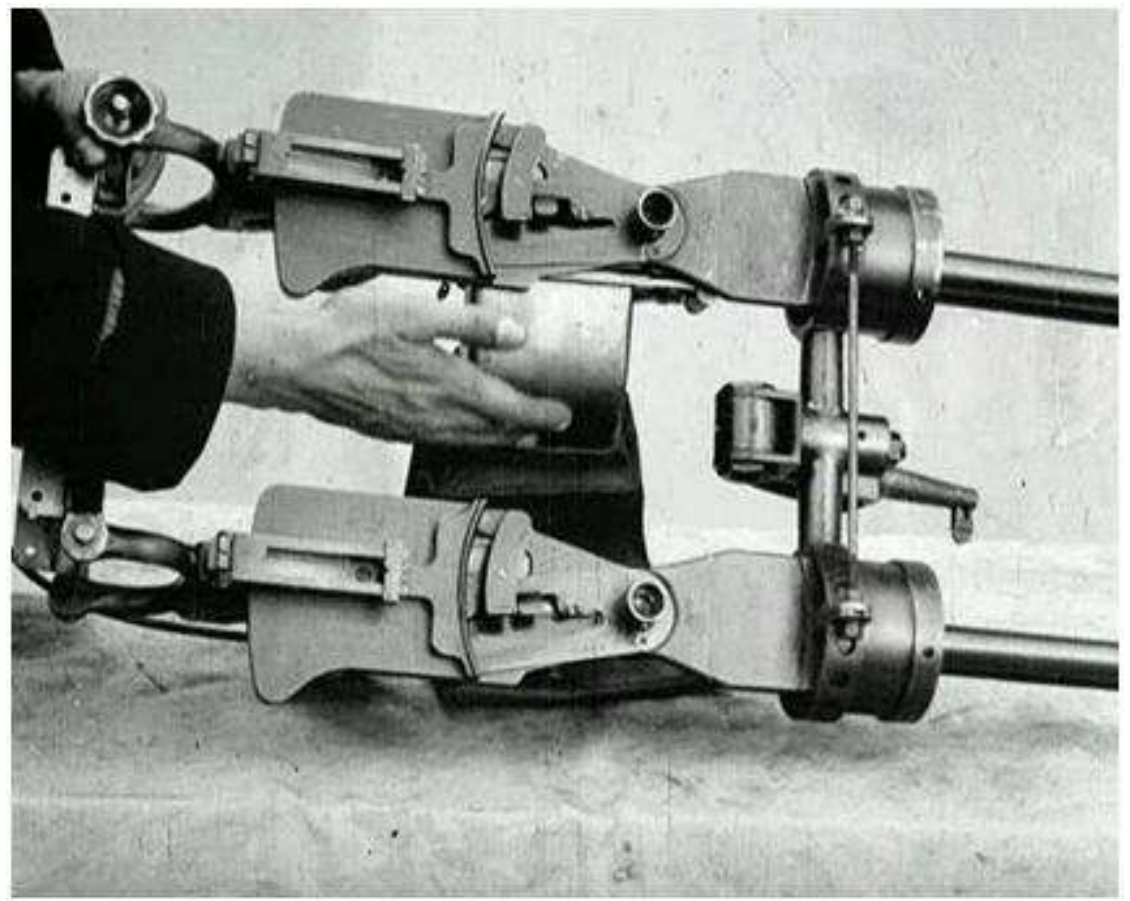

Le mitrailleur d'avion au front, film d'instruction. Démontage et vérification de la mitrailleuse double Lewis (photogramme). Opérateur inconnu.

(c) ECPAD, date inconnue, Réf. 14.18 A 501, noir et blanc, muet, Time code 00:07:10. 
Figure 10

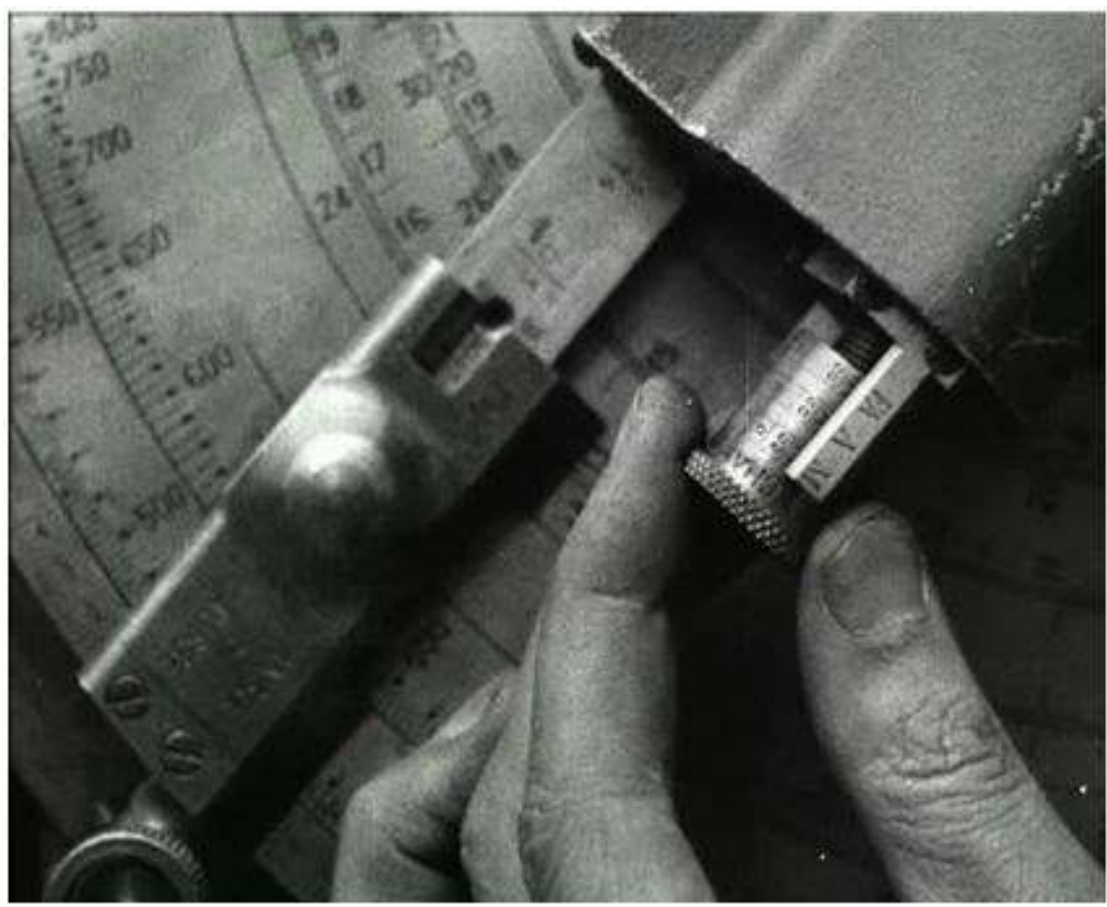

Canon de 155 mm court Schneider, le fonctionnement de la table de tir (photogramme). Opérateur inconnu.

(c) ECPAD, date inconnue, Réf. 14.18 A 428, noir et blanc, muet, Time code 00:07:58.

21 Les opérateurs de prises de vues des Sections photographique et cinématographique de l'armée poursuivent en 1916 leurs reportages dans les établissements de la région : usines Citroën du quai de Javel, construction automobile aux usines Renault de Billancourt, fabrication de munitions à l'usine Clément-Bayard de Levallois où on voit des enfants usiner et transporter des obus de moyen calibre, usine Ruggieri de Saint-Ouen où des femmes effectuent de l'usinage de précision sur de petites pièces. Les reporters s'intéressent aussi au secteur des fournitures militaires: fabrication des lunettes de protection contre les gaz aux usines Pathé, de projecteurs et matériels d'optique chez Gaumont, confection des casques aux établissements Dupeyron et Simon (voir fig. $\mathbf{n}^{\circ} \mathbf{2 3}$ ). L'industrie pharmaceutique n'est pas oubliée, avec la fabrication des sérums à l'institut Pasteur (fig. $\mathbf{n}^{\circ} \mathbf{1 1}$ ). En effet, l'armée, qui vaccine et revaccine en série ses effectifs contre la typhoïde depuis le début de la guerre, a besoin de doses en grande quantité. 


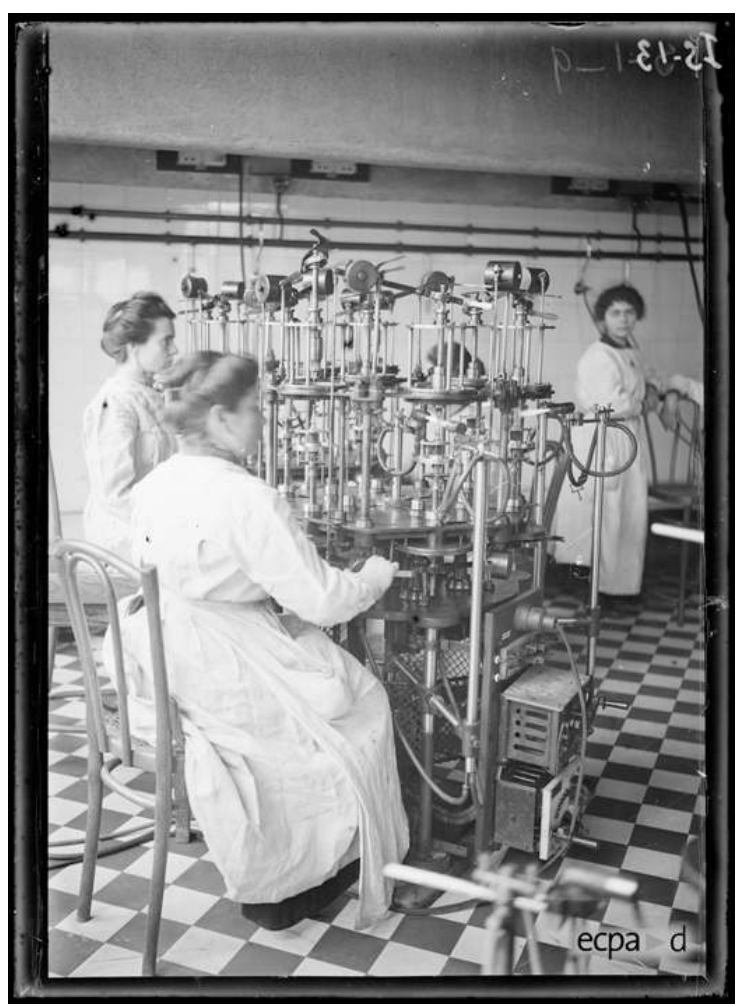

GARCHES (HAUTS-DE-SEINE). INSTITUT PASTEUR. FABRICATION DES SÉRUMS. MACHINE À FERMER LES FLACONS.

PHOT. BRESSOLLES, PAUL. @ ECPAD, DÉCEMBRE 1916, RÉF. SPA 3 IS 13.

S'il est important de mettre en valeur l'effort industriel de guerre, il ne l'est pas moins de montrer que les fabrications traditionnelles françaises ne sont pas interrompues. C'est pourquoi les opérateurs militaires s'intéressent également aux produits de luxe, notamment à la parfumerie qui fait l'objet de trois reportages en 1916, l'un aux établissements Pinaud à Pantin et deux autres chez Roger \& Pellerin à Levallois-Perret, par deux photographes différents. Ce secteur, décidément emblématique du raffinement des produits français, fera encore l'objet de reportages en 1917. De même, l'industrie du cinéma continue à fonctionner malgré la mobilisation d'un grand nombre d'opérateurs dont plusieurs servent au sein de la Section cinématographique de l'armée. Aux usines Gaumont des Buttes-Chaumont, alors que les ouvriers et ouvrières fabriquent des gaines d'obus, des pieds de hausse et des appareils de prises de vues aériennes pour l'armée, un plateau de tournage semble être resté en activité avec ses décors et son mobilier, dans les deux grandes serres (fig. $\mathbf{n}^{\circ} \mathbf{1 2}$ ) construites en 1910 en prolongement du studio édifié en $1905^{23}$. Les opérateurs visitent également divers ateliers de tissage et de travail du cuir implantés en région parisienne. Dans le nécessaire arbitrage à opérer entre les besoins du front et ceux de l'arrière, les clichés réalisés par la Section participent d'une propagande destinée à montrer que le partage se réalise au mieux entre la satisfaction de l'industrie militaire et celle des fabrications civiles. 


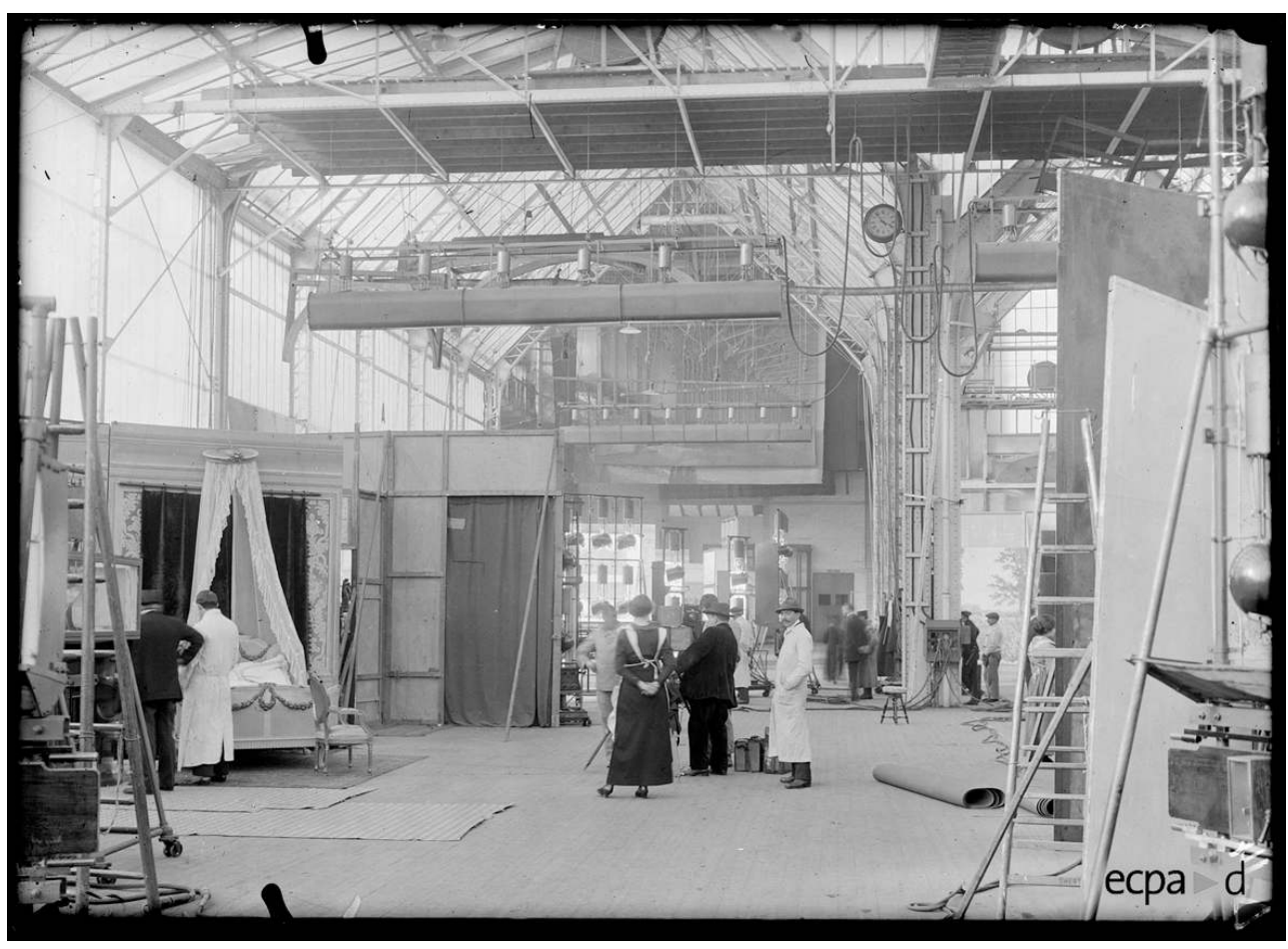

PARIS. ÉTABLISSEMENTS GAUMONT. LE THÉÂTRE (INTÉRIEUR).

PHOT. BAgUET, ERNEST. (C) ECPAD, AVRIL 1916, RÉF. SPA 2 Y 14.

\section{7-1918, l'essor de l'automobile et de l'aviation}

Ces deux secteurs, déjà très actifs et très bien représentés dans la région parisienne avant le déclenchement du conflit, vont connaître un développement extraordinaire. À la fin de 1915 , les grands constructeurs automobiles emploient au total environ 24000 personnes à Paris et en proche périphérie. Si tous ont d'abord détourné une plus ou moins grande partie de leur capacité pour produire des munitions, ils vont se consacrer à nouveau à leur spécialité en développant la construction de camions pour le transport des troupes et des fournitures, de tracteurs d'artillerie pour véhiculer sur route et en terrain accidenté des pièces de plus en plus lourdes, de véhicules spéciaux (autos blindées, voituresprojecteur) et de chars d'assaut, dans le cas de Renault. Dans le secteur aéronautique, les entreprises sont de plus petite taille - Farman compte 1400 ouvriers en 1915 et le motoriste Salmson 1200 - mais elles sont en plein essor et commencent à s'étendre en banlieue. À la fin du conflit, l'aviation emploie au total 186000 personnes, dont 40000 sur la seule commune de Boulogne-Billancourt. Seul ce secteur sera développé ici.

En 1914, l'aviation est une industrie presque entièrement située dans la région parisienne, tant pour la fabrication des appareils que pour celle des moteurs, avec les entreprises Farman, Voisin, Salmson (fig. $\mathbf{n}^{\circ}{ }^{\circ}$ ) et Renault à Boulogne-Billancourt, Morane-Saulnier à Puteaux, Nieuport à Suresnes, Letord à Meudon-Val Fleury, Blériot et Clerget-Blin à Levallois-Perret, Lorraine-Dietrich à Argenteuil, Hispano-Suiza à Colombes, Gnome à Gennevilliers et Le Rhône à Paris, boulevard Kellermann. Lorsque la capitale est menacée, avant la contre-offensive de la Marne, certains constructeurs ont prévu des solutions de repli vers Lyon, qu'ils n'auront pas à mettre en œuvre ${ }^{24}$. Deux autres constructeurs 
viennent les rejoindre, fuyant l'avancée allemande: Caudron, auparavant installé au Crotoy, et Hanriot, anciennement à Reims. L'histoire de l'industrie aéronautique française pendant la Grande Guerre est un vaste sujet qui mériterait un long développement à lui seul. C'est pourquoi il sera abordé ici sous un angle emblématique, celui des moteurs rotatifs qui ont équipé plus de la moitié des appareils entre 1914 et 1918 et ont été fabriqués à environ 50000 exemplaires, grâce essentiellement aux constructeurs GnomeRhône et Clerget-Blin. L'essor de ce type de moteurs et son maintien en usage pendant quatre ans, malgré l'existence de moteurs à cylindres en $\mathrm{V}$ ou en ligne plus puissants, sont dus à la conjonction de plusieurs facteurs : la nécessité de faire voler des aéronefs légers avec des machines développant une forte puissance pour un poids le plus faible possible, les progrès de la voilure des avions qui étaient moins rapides que ceux de la motorisation ${ }^{25}$, l'inventivité de quelques ingénieurs motoristes et le succès de ces engins auprès des aviateurs.

$\mathrm{Au}$ début de l'aviation, on monte sur les appareils des moteurs classiques. Ils sont cependant lourds et nécessitent des circuits de refroidissement par eau qui grèvent leur poids. En outre, en cas de combat aérien, ces circuits risquent d'être traversés par les projectiles ennemis, rendant le moteur inutilisable. Le moteur en étoile, qui existe depuis les années 1890 sur les cycles Millet, pourrait offrir des perspectives. En 1909, les frères Séguin imaginent à partir de ce concept un moteur révolutionnaire: ils créent un 7 cylindres en étoile, baptisé Gnome oméga, dont l'ensemble du carter et des pistons tourne autour d'un vilebrequin fixe (dans les moteurs fixes, c'est le vilebrequin qui tourne en actionnant les pistons dans les cylindres). Cette innovation va ouvrir une voie nouvelle pour la motorisation aéronautique. Le système des frères Seguin permet d'alléger la machine : en effet, la rotation fait que le moteur constitue son propre volant d'inertie. Elle améliore par ailleurs le refroidissement par les ailettes, même lorsque l'avion est à l'arrêt, de sorte qu'un circuit d'eau n'est pas nécessaire. L'admission du mélange air-essence, dispositif insolite, se fait à travers le vilebrequin qui est creux; il entre dans les chemises par une soupape percée dans les pistons. Par ce système, le carburant arrive déjà à bonne température dans les cylindres et il n'y a pas besoin d'un circuit de réchauffage. L'échappement se fait à l'air libre par une soupape en tête de chaque cylindre. L'ensemble est lubrifié par de l'huile de ricin qui passe également par le vilebrequin et qui est éjectée en tête des cylindres par la force centrifuge, en même temps que les gaz d'échappement, sans recyclage. Les réglages sont délicats et varient d'un moteur à l'autre mais, une fois mis au point, le moteur Gnome oméga tourne avec régularité et développe $50 \mathrm{ch}$ pour $79 \mathrm{~kg}$; il rencontre immédiatement un grand succès auprès des aviateurs, qui le baptisent familièrement «rototo ». Un an plus tard, l'ingénieur Louis Verdet construit pour la société Le Rhône un clone du moteur Gnome oméga en améliorant notamment la carburation. Le Rhône et Gnome créent ensuite chacun un 9 cylindres rotatif. De son côté, l'ingénieur Pierre Clerget construit pour Clément-Bayard le même type d'engin. En 1913, ayant monté sa propre entreprise avec Émile Blin qui lui apporte les capitaux, il crée, en concurrence des deux autres firmes, un moteur rotatif 9 cylindres de $130 \mathrm{ch}$ (fig. $\mathbf{n}^{\circ} \mathbf{1 4}$ ). Ainsi, en 1914, trois sociétés de la région parisienne produisent ce type de machine. 
Figure 13

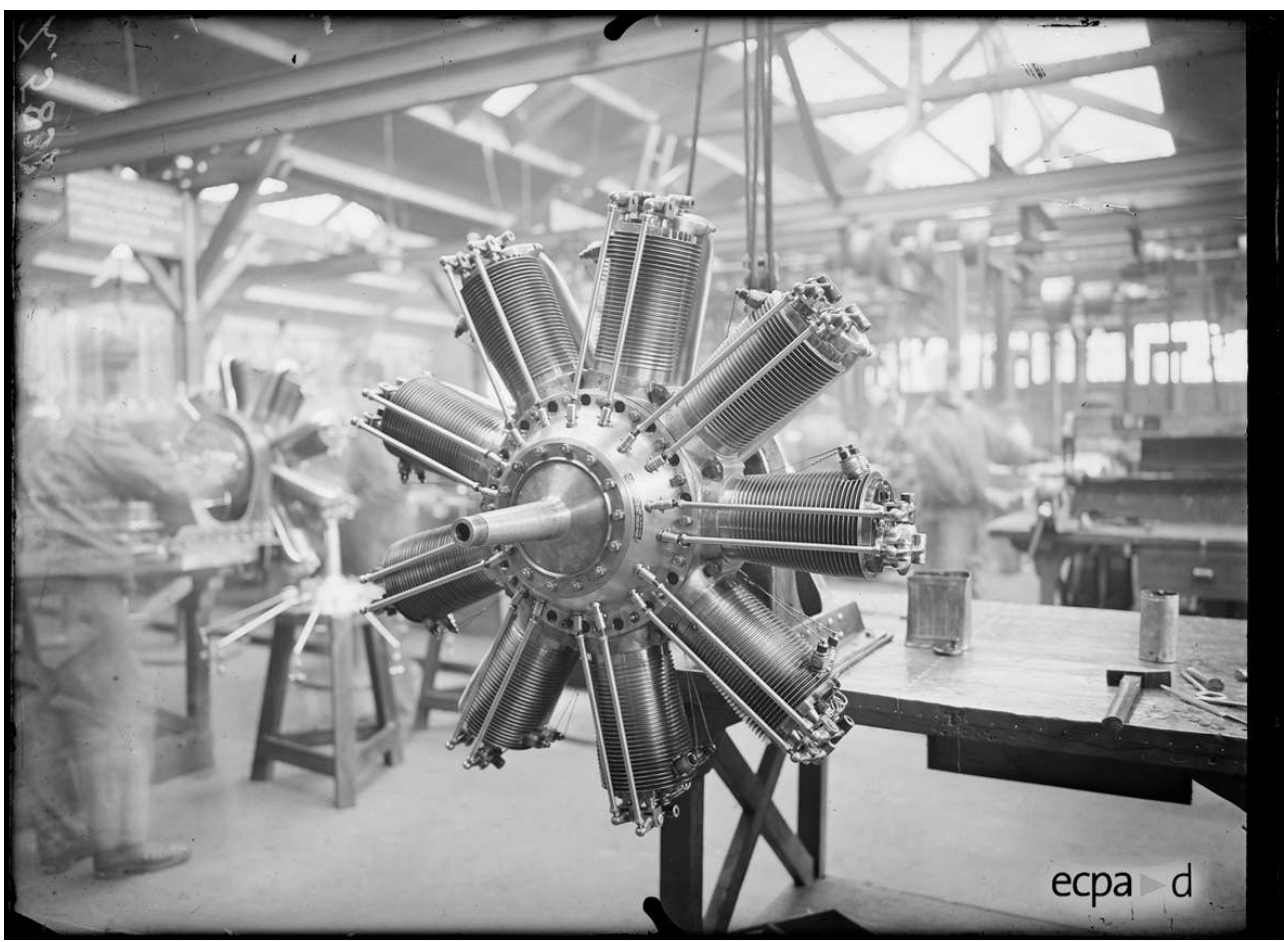

Moteur Clerget 130 ch, 1200 tours, 170 kg à l'usine Salmson de Billancourt (Hauts-de-Seine). PHOT. LEMARE. (C) ECPAD, JANVIER 1918, RÉF. SPA 171 z 5837.

Figure 14

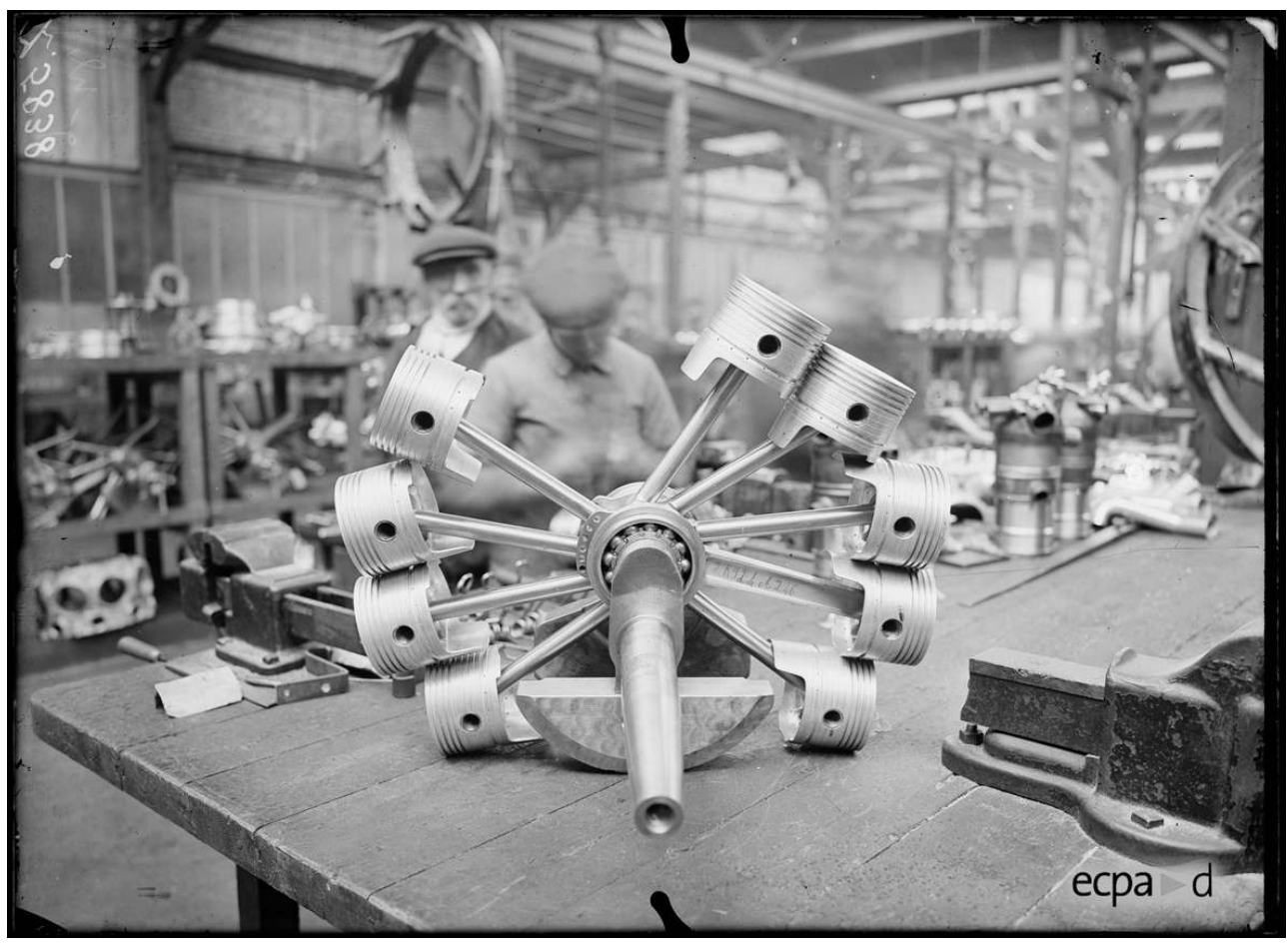

L'ARBRE, LES BIELLES ET LES CYLINDRES d'UN MOTEUR EN ÉTOILE À L'USINE SALMSON DE BILLANCOURT (HAUTS-DE-SEINE).

PHOT. LEMARE. () ECPAD, JANVIER 1918, RÉF. SPA 171 z 5838. 
Quand la guerre éclate, les rotatifs sont encore peu répandus dans le domaine militaire. L'aviation, dispersée sur le front, n'est pas la priorité de l'armée et celle-ci utilise des moteurs de technologie plus ancienne. Le général Hirschauer, nommé directeur de l'Aéronautique en octobre 1914, la réorganise et commande en masse et dans l'urgence de nouveaux avions en privilégiant quatre modèles. Un peu plus de 500 appareils sont fabriqués avant la fin de l'année 1914 mais la production des moteurs ne suit pas : la construction des cellules, essentiellement en bois et toile, est plus rapide que celle des moteurs. La diversification de l'aviation en 1915 (naissance de la chasse; nécessité d'une aviation de bombardement tactique sur le terrain, d'une force de bombardement stratégique pour frapper en profondeur le territoire ennemi et d'une aviation de reconnaissance aérienne pour les réglages d'artillerie) accroît encore les besoins. Or, les usines sont sous-dimensionnées. Une des premières décisions du gouvernement est d'activer le rapprochement, au début de 1916, des entreprises Gnome et Le Rhône qui fusionnent en une seule entité, la Société des moteurs Gnome et Rhône (fig. $\mathbf{n}^{\circ}{ }^{\circ}$ ) (fig. $\mathbf{n}^{\circ}$ 16). La production de la SMGR va ainsi passer de 600 moteurs environ au deuxième semestre 1914 à plus de 13000 en 1918, malgré la chute d'un obus sur l'usine de l'avenue Kellermann le 11 avril 1918, pendant les bombardements sur la capitale. La production totale de l'entreprise Gnome et Rhône pendant la Grande Guerre est de plus de 23000 moteurs rotatifs.

\begin{tabular}{|l|l|l|l|l|l|}
\hline SMGR & $\mathbf{1 9 1 4}$ & $\mathbf{1 9 1 5}$ & $\mathbf{1 9 1 6}$ & $\mathbf{1 9 1 7}$ & $\mathbf{1 9 1 8}$ \\
\hline Chiffre d'affaires en millions de F & ND & 44 & 75 & 100 & 93 \\
\hline Bénéfices en millions de F & 9,6 & 13 & 14 & 7,7 & ND \\
\hline Nombre d'employés & 2000 & 3000 & 5000 & ND & ND \\
\hline
\end{tabular}

Activité de la société des moteurs Gnome et Rhône, d'après Lemaire, René, Pecastaingts, Pierre et Hartmann, Gérard, Produire en masse des moteurs d'aviation, 1914-1918 (voir note 24).

Les chiffres sont impressionnants mais l'entreprise subit de fréquents retards de paiement de l'État, voit le prix des matières premières augmenter et doit aussi passer au compte des pertes son usine de Moscou tombée aux mains du nouveau pouvoir russe en $1917^{26}$. Par ailleurs, l'État ponctionne la SMGR en l'obligeant à souscrire sept millions de francs de bons de la Défense nationale en 1915, puis dix millions de francs en 1916.

La technologie française des moteurs rotatifs essaime à l'étranger. Le moteur Clerget-Blin 9 cylindres, bien qu'ayant été homologué par le service technique de l'aéronautique (STAé) à Chalais-Meudon en 1914, n'est pas retenu dans les programmes d'équipements français. Pourtant, la Grande-Bretagne le choisit pour en équiper ses hydravions de combat et ses avions de chasse, notamment le Sopwith camel qui remporte un très grand nombre de victoires au cours du conflit. Les usines françaises ne pouvant produire suffisamment de moteurs, les Anglais le fabriquent sous licence en Angleterre en y apportant des améliorations, notamment des pistons en aluminium ${ }^{27}$. En 1916, toujours dans le but d'augmenter la puissance en gardant la légèreté, Pierre Clerget crée un moteur rotatif en étoile de 11 cylindres et 23 litres, à taux de compression variable et 
développant 200 ch, qui équipe les bombardiers Sopwith Strutter. En 1917, il prépare un 16 cylindres en $X$ de 400 ch qui ne passera jamais au stade de la fabrication en série, rattrapé par l'armistice. Pendant le conflit, la production totale des moteurs Clerget-Blin est d'environ 30000 pièces (France et Grande-Bretagne).

Figure 15

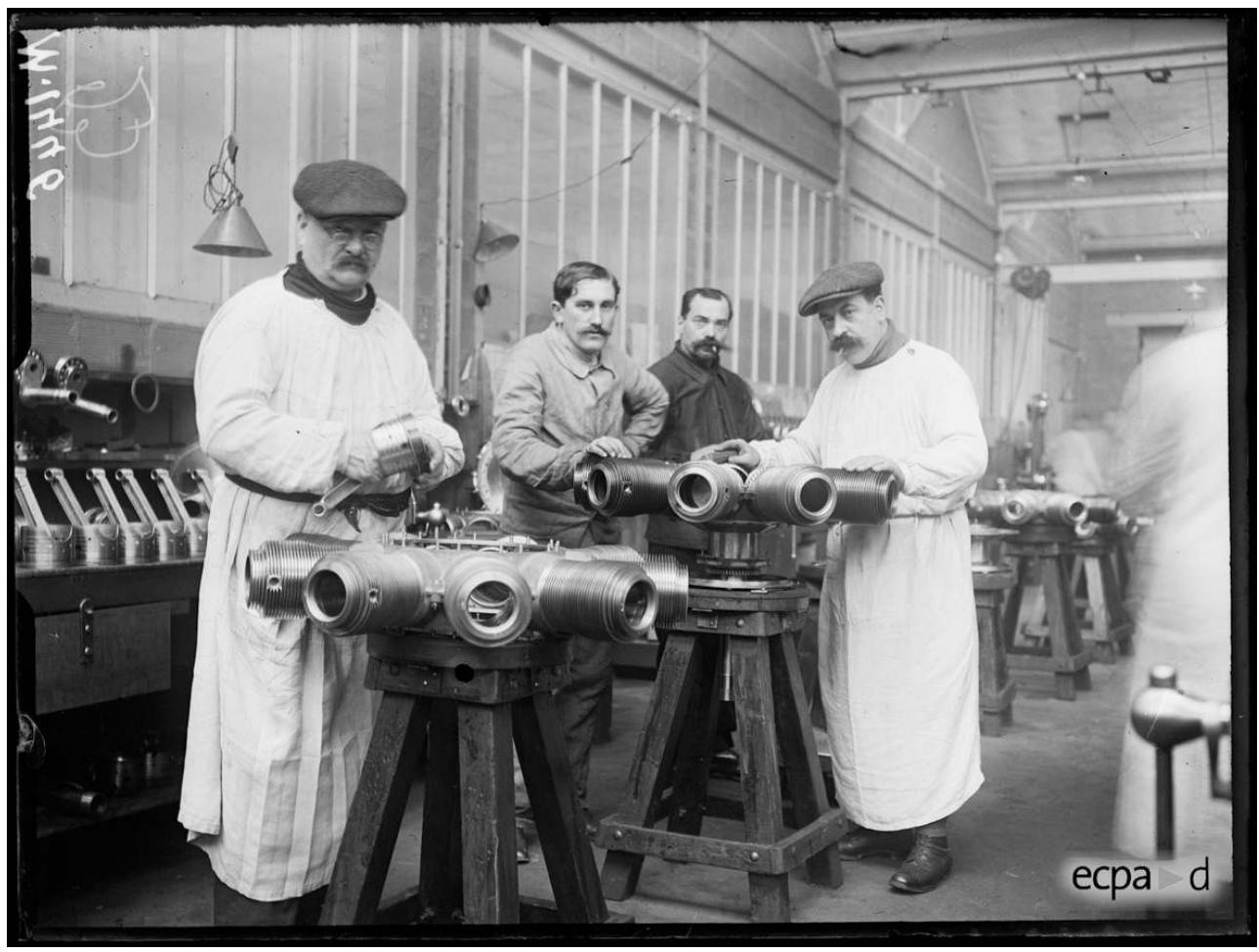

ATELIER DES MOTEURS GNOME À ARgENTEUIL (VAL-D'OISE).

PHOT. MOREAU, ALBERT. ( C ECPAD, JANVIER 1916, RÉF. SPA 60 M 1446. 
Figure 16

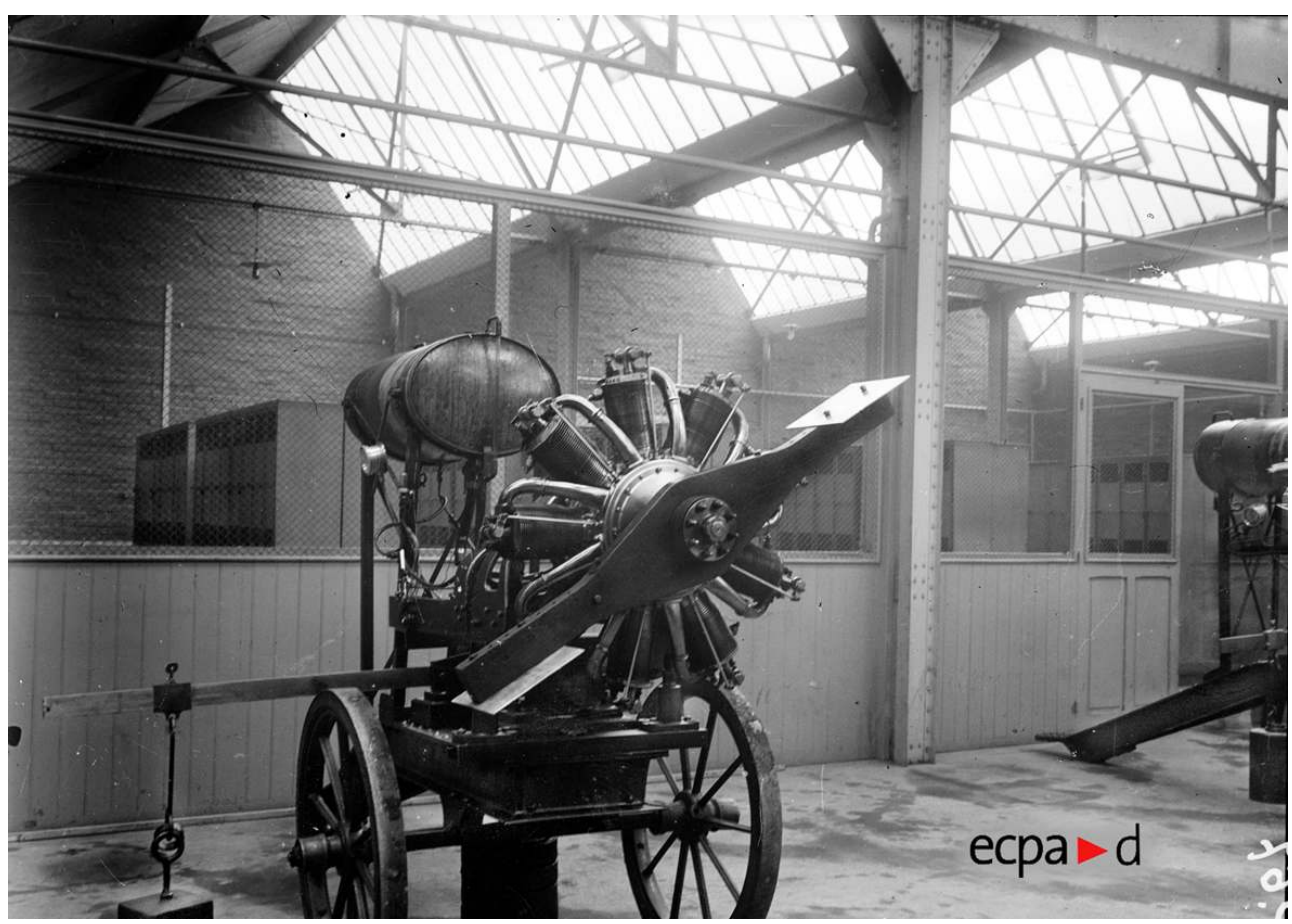

ARgENTEUIL (VAL-D'OISE). MOTEUR GNOME AU BANC D'ESSAI SUR UN AFFÛT DE CANON, AVEC UNE HÉLICE-FREIN.

PHOT. BOUSSUgE, GABRIEL. C ECPAD, JANVIER 1916, RéF. SPA 8 P 67.

Les moteurs rotatifs équipent l'essentiel de la chasse jusqu'à la fin de 1916. Tout au long du conflit, on assiste entre la France et l'Allemagne à une course à la puissance, à l'aérodynamisme, à la maniabilité et à la disposition des instruments de tir sur les appareils. Les modèles d'avions connaissent une obsolescence très rapide et sont vite périmés. Il faut sans cesse innover tout en continuant à produire et réparer les moteurs existants, qui nécessitent des révisions très fréquentes ou qui cassent. En juin 1915, l'aviation allemande se dote du Fokker E1 à moteur Oberursel, une copie du rotatif Gnome fabriqué sous licence en Allemagne. Cet avion vole parfois aussi avec une machine Le Rhône capturée. En effet, dès qu'un appareil français à moteur rotatif est pris (fig. ${ }^{\circ}{ }^{\circ}$ 17), les aviateurs allemands s'empressent de réutiliser celui-ci sur leurs propres avions. C'est le cas du pilote Manfred von Richthofen, alias "le Baron Rouge », qui sera abattu aux commandes d'un avion sur lequel est monté un moteur français. Le Fokker E1 peut tirer à travers l'hélice et fait la loi dans les airs, jusqu'à la sortie d'un concurrent français, le BB Nieuport, beaucoup plus agile et doté d'une très grande vitesse ascensionnelle. Pendant un an et demi, les versions successives de ces deux appareils, toujours équipées de moteurs rotatifs dont la puissance se développe, vont se voler la vedette dans les combats aériens. 


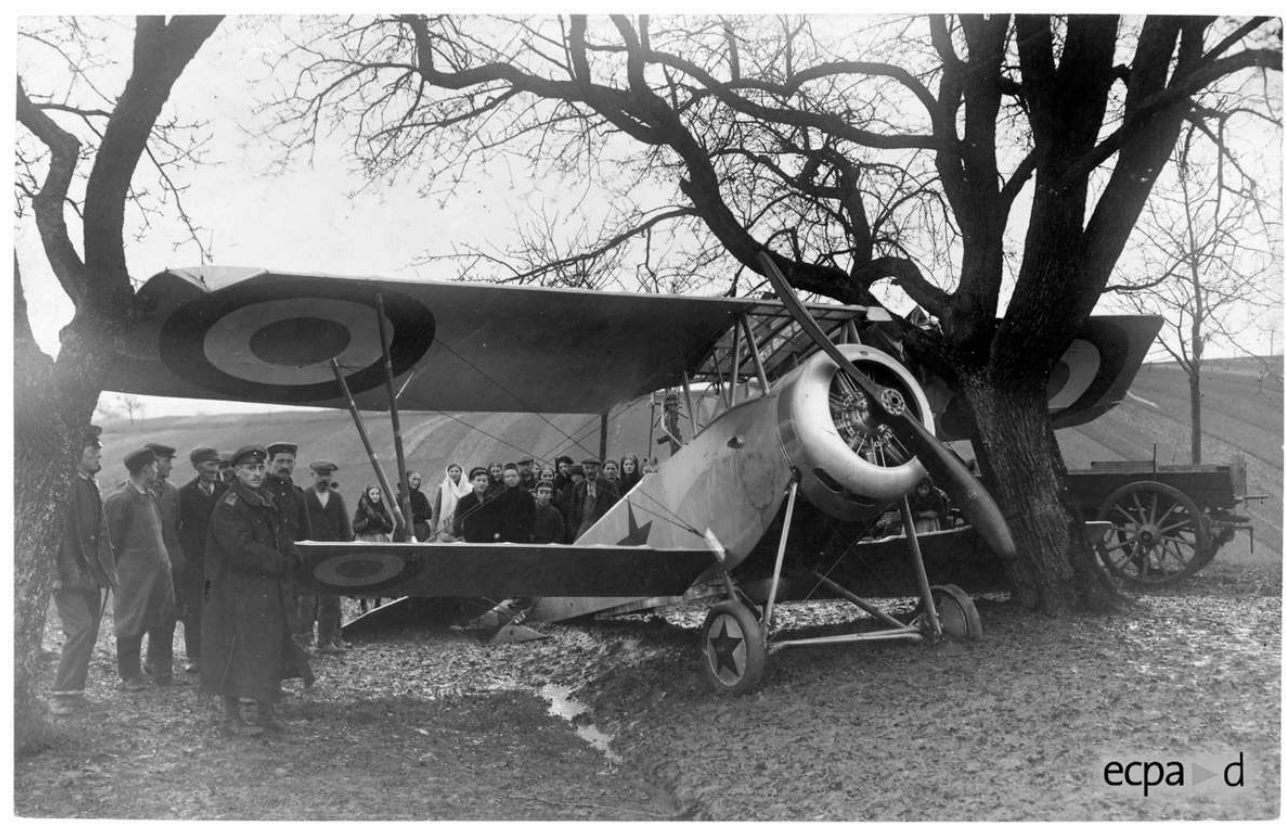

[UN AVION NIEUPORT ACCIDENTÉ CAPTURÉ PAR LES ALLEMANDS]. PHOT. INCONNU.

(c) ECPAD, COLLECTION LEFORT, DATE INCONNUE, RÉF. D186-1-12.

31 Les moteurs fixes n'ont pourtant pas dit leur dernier mot. À la fin de 1916, après six mois d'essais, la Société de production des aéroplanes Deperdussin sort un nouvel appareil, le SPAD S.VII à moteur Hispano-Suiza de 8 cylindres en V développant $180 \mathrm{ch}$, bientôt aux prises avec un nouveau modèle allemand d'Albatros, le D III, doté lui d'un puissant moteur en ligne Mercedes ou Benz ${ }^{28}$. Ces nouvelles machines, grâce à la surcompression et à l'utilisation de matériaux plus légers, l'aluminium notamment, concurrencent désormais les productions sophistiquées de Gnome-Rhône et de Clerget-Blin.

En avril 1917, un rapport du Sénat sur l'état de l'aviation ${ }^{29}$ souligne une crise des moteurs. Les chiffres de production de février sont en retrait de $40 \%$ sur les prévisions, tant pour les rotatifs que pour les fixes de type Hispano-Suiza (fig. $\mathbf{n}^{\circ} 18$ ) ou autre. L'industrie n'arrive plus à tenir la cadence en raison de difficultés d'approvisionnement en énergie et en carburant pour alimenter les essais. Toutefois, les chiffres semblent aussi révéler que les moteurs en ligne pourraient bien désormais avoir le vent en poupe. En effet, en mars 1917, Hispano-Suiza, avec 294 machines livrées, réussit à redresser fortement sa production et à tenir les objectifs figurant dans une note de service de décembre 1916, qui prévoyait 280 moteurs, tandis que la production des moteurs rotatifs ne se rétablit qu'avec lenteur. Ceci illustre le fait que, comme le souligne Gérard Hartmann ${ }^{30}$, le temps de fabrication d'un moteur fixe à cylindres en ligne ou en $\mathrm{V}$ est trois fois moindre que celui d'un rotatif de même puissance. Il a en outre l'avantage de pouvoir être fabriqué dans l'industrie automobile, l'inverse étant plus malaisé : le moteur rotatif, avec sa haute technologie, son usinage et son montage très précis, demande un savoir-faire spécifique, il ne se prête pas à la fabrication en grande série sur des chaînes standardisées ${ }^{31}$. Les constructeurs de moteurs rotatifs en restent donc à une organisation traditionnelle de la fabrication, moins productive mais qu'ils poussent au maximum, au détriment souvent de la sécurité et au prix de nombreux accidents du travail. 


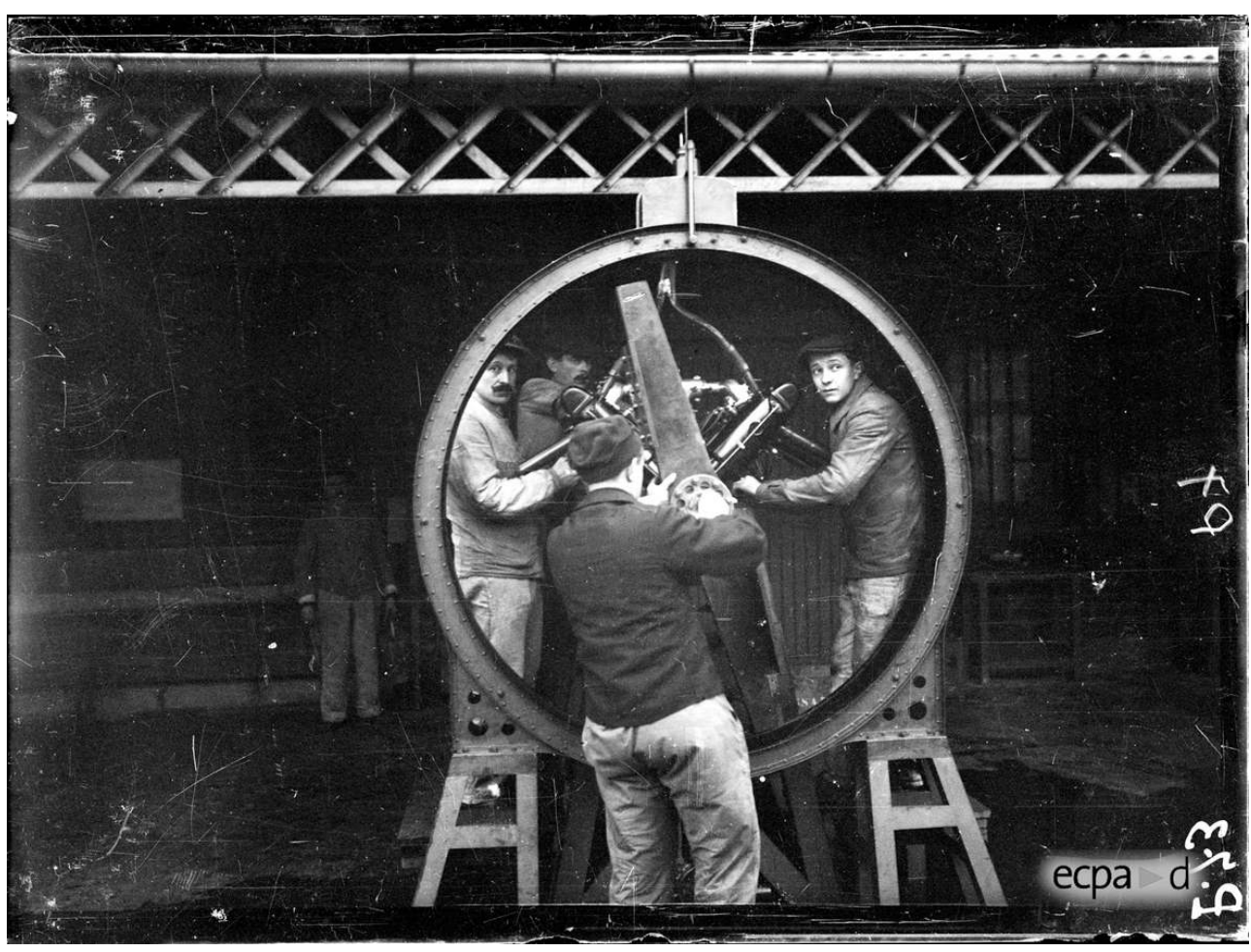

MOTEUR HISPANO-SUIZA SUR UN BANC D'ESSAI À BOIS-COLOMBES (HAUTS-DE-SEINE).

PHOT. BOUSSUgE, GABRIEL. () ECPAD, JANVIER 1916, RÉF. SPA 8 P 73.

Outre leur fabrication compliquée, les moteurs rotatifs posent depuis le début quelques problèmes d'utilisation. Le pilotage est délicat en raison du fort effet de couple dû à la rotation du moteur : l'avion a tendance à se cabrer lors des virages à gauche et à piquer lors des virages à droite. Le réglage de la puissance est difficile, bien qu'il ait été amélioré par un système complexe d'allumage permettant de n'utiliser que 3 ou 6 des 9 cylindres. La consommation d'huile est considérable - un litre d'huile pour cinq litres de carburant sur les premiers modèles - et son éjection à l'air libre pose des problèmes de visibilité au pilote, en partie résolues par l'adjonction d'un capot. Avec une révision toutes les vingt heures, la maintenance est deux fois plus lourde que sur les moteurs fixes. En outre, la puissance reste limitée ${ }^{32}$. Cependant, les « rototos » continuent à tourner sur les modèles d'avions existants et à équiper de nouveaux appareils. Dans le même temps, d'autres constructeurs expérimentent des modèles fixes en étoile ou en double étoile, de plus en plus gros et puissants, dont certains restent à l'état de prototype (fig. $\mathbf{n}^{\circ} \mathbf{1 9}$ ). 
Figure 19

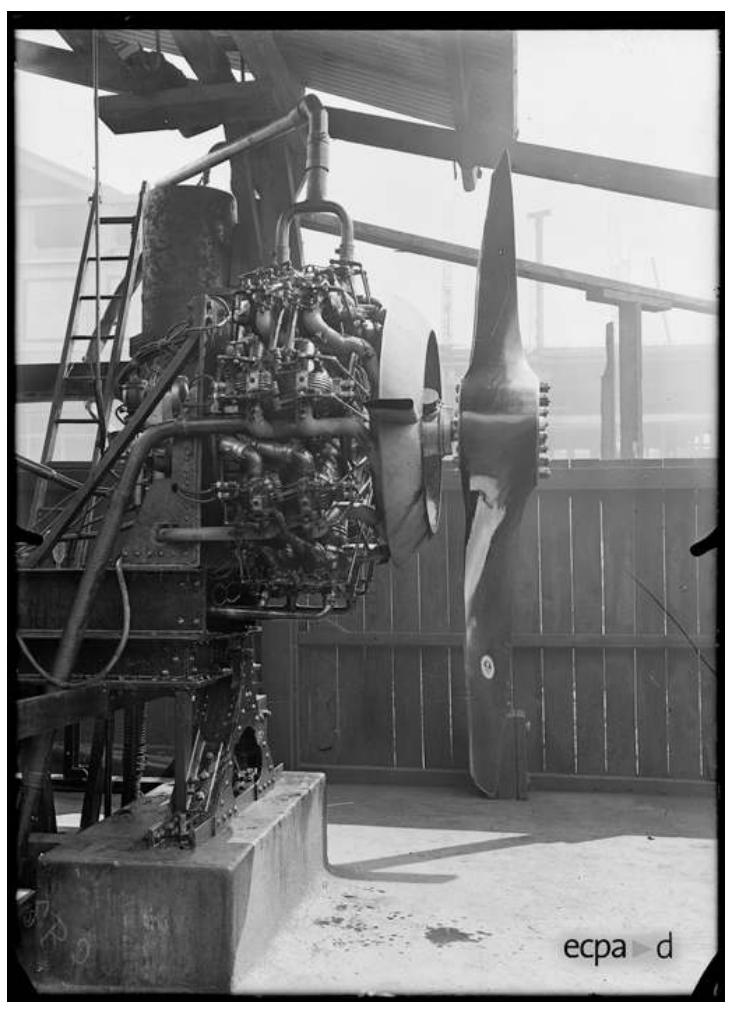

USINE d'AVIATION SALMSON (BILLANCOURT ?). MOTEUR DE 500 CH, 18 CYLINDRES AU BANC D'ESSAI.

PHOT. QUESTE, PAUL. @ ECPAD, JUIN 1918, RÉF. SPA 152 B 7404.

Comme pour l'artillerie, le cinéma scientifique se met au service de l'industrie et de la pédagogie. Le Service cinématographique technique de la direction des Inventions réalise des films sur le fonctionnement interne des moteurs rotatifs. L'un d'eux, particulièrement pédagogique, porte sur le moteur Gnome et Rhône $9 \mathrm{C}$ et montre les phases successives de son fonctionnement (fig. $\mathbf{n}^{\circ} \mathbf{2 0}$ ) : partant d'une vue externe de l'engin en rotation, il fait plonger le spectateur dans les profondeurs de la mécanique par une série de plans de plus en plus rapprochés, en coupe; l'admission, la compression et l'éjection des gaz sont matérialisées pour la caméra par de la ouate, tandis qu'un assistant présente des ardoises explicatives et actionne les pièces. Ce document animé était peut-être destiné à la formation théorique des mécaniciens chargés de l'entretien des appareils sur le terrain.

Figure 20
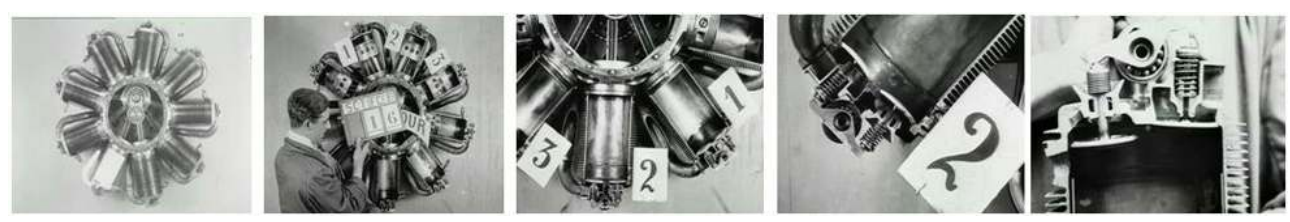

Film d'instruction sur le moteur Le Rhône $9 \mathrm{C}$ (photogrammes). Opérateur Blanc, Charles.

(c) ECPAD, 1917, Réf. 14.18 A 1091, N\&B, muet, durée 4 mn.

D'autres films montrent la fabrication complète d'un appareil, par exemple celle d'un Bréguet 14 A2, biplace d'observation et de bombardement, visible sur le film L'Effort de l'aviation française (réf. 14.18 A 506). 
Après l'armistice, près de 30000 moteurs d'avions en stock ou en cours de livraison se retrouvent sur le marché. Du jour au lendemain, les constructeurs ne reçoivent plus aucune commande. Clerget-Blin qui, sur les conseils de Louis Loucheur, a réinvesti en 1918 la totalité de ses bénéfices pour augmenter sa production de moteurs d'avions dans la perspective de la poursuite de la guerre, subit un coup d'arrêt. Les industriels qui ont reçu des commandes de guerre sont, après une loi de 1920, fortement imposés sur les revenus engrangés pendant les hostilités. Certains s'en sortent car ils ont gardé leur activité traditionnelle, tels les constructeurs automobiles, ou parce que leur siège social est à l'étranger (Hispano-Suiza). Clerget-Blin doit verser 500 millions de francs. Ruiné, Eugène Blin se suicide. L'entreprise est dissoute et tout le personnel licencié. Pierre Clerget entre alors au Service technique de l'aéronautique et doit continuer à éponger la dette fiscale de la défunte entreprise sur son salaire. Il se consacre désormais aux moteurs d'aviation diesel. Malgré le décès des ingénieurs Louis Séguin en janvier 1918 et Louis Verdet en novembre, victime de la grippe espagnole, la société Gnome et Rhône se restructure et se diversifie temporairement vers le cycle, l'automobile et les machines à coudre, avant de se relancer dans l'aéronautique à partir de 1923. Elle est intégrée à la SNECMA après la Seconde Guerre mondiale.

Cependant, en 1918, l'industrie des moteurs d'aviation français a su conserver et affirmer sa prééminence mondiale. Elle a réussi à produire 44000 engins en onze mois et 4450 pour le seul mois d'octobre, soit le double de ce qu'ont produit la Grande-Bretagne et l'Allemagne pour la même période, et le triple par rapport aux fabrications américaines ${ }^{33}$. À la fin de la guerre, la France détient $40 \%$ de la construction mondiale. Cette industrie a essaimé à l'étranger par le biais des licences concédées aux pays alliés, qui ont décliné des gammes locales. Elle a également inspiré les constructeurs allemands qui ont utilisé à leur profit certains concepts inventés par les ingénieurs motoristes français. Les avancées technologiques réalisées sous la forte pression des commandes militaires sont considérables.

\section{Les conditions de la production : énergie, outillage, rationalisation}

Le manque de charbon, et par conséquent la difficulté d'approvisionner les machines à vapeur, donne un coup d'accélérateur à l'industrie électrique. Au début de la guerre, les six compagnies qui fournissaient l'électricité à la capitale par secteur viennent d'être regroupées en une société unique, la Compagnie parisienne de distribution d'électricité (CPDE), qui délivre une puissance de pointe de $65000 \mathrm{~kW}$, suffisante pendant les deux premières années du conflit car la consommation des particuliers stagne. Mais à la fin de 1916, afin d'assurer la fourniture d'énergie aux industries travaillant pour la défense nationale, il s'avère nécessaire de réglementer de façon drastique la consommation privée. Une ordonnance du préfet de Police, dont l'affiche est photographiée dans une rue par l'opérateur Albert Moreau ${ }^{34}$, établit pour l'hiver 1916-1917 un barème basé sur les consommations de l'année précédente et les restreignant fortement. Il est stipulé que les dépassements donneront lieu à des jours de privation de courant. La capitale fait alors appel aux compagnies d'électricité privées de la banlieue (notamment la Société d'électricité de Paris à Saint-Denis et l'usine du Triphasé à Asnières). Malgré l'usage croissant de l'électricité, le gaz est encore très utilisé, comme le montre la salle des machines des abattoirs de la Villette : la force motrice y est fournie par des machines à 
piston et un compresseur fabriqués par la Compagnie des moteurs à gaz et des constructions mécaniques, qui a ses ateliers rue de la Croix-Nivert (fig. $\mathbf{n}^{\circ} \mathbf{2 1}$ ).

Figure 21

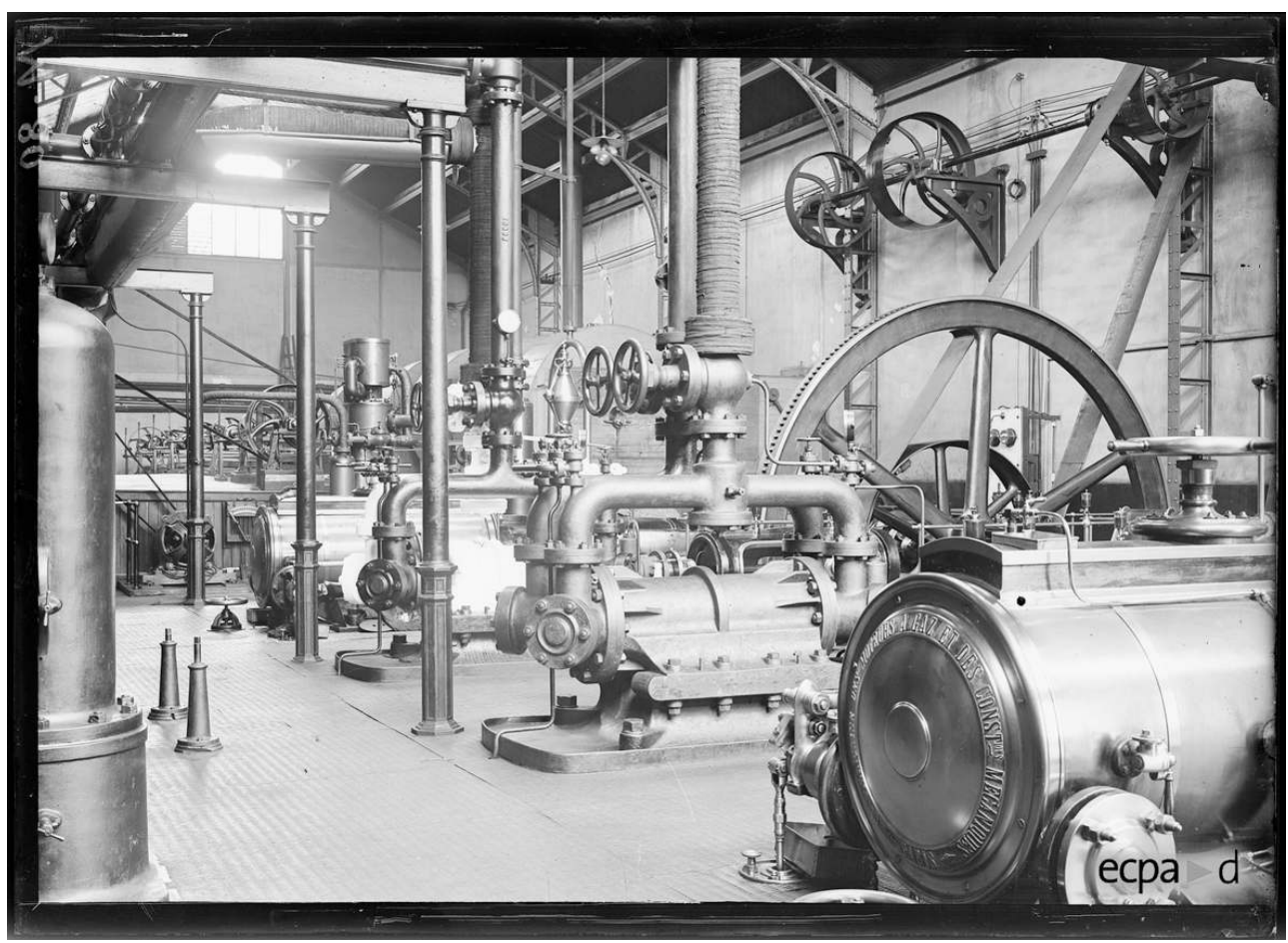

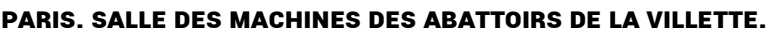

PHOT. MOREAU, ALBERT. (C) ECPAD, JUIN 1918, RÉF. SPA 8 M 80.

Le gaz de la région parisienne provient en partie d'un établissement de Clichy, l'usine de la Société du gaz de Paris, où travaillent pendant la guerre des ouvriers algériens (fig. $\mathbf{n}^{\circ}$ 22). En 1914, elle possède sept gazomètres qui produisent plus de 3000 mètres cubes de gaz à partir de la distillation du schiste bitumeux. 


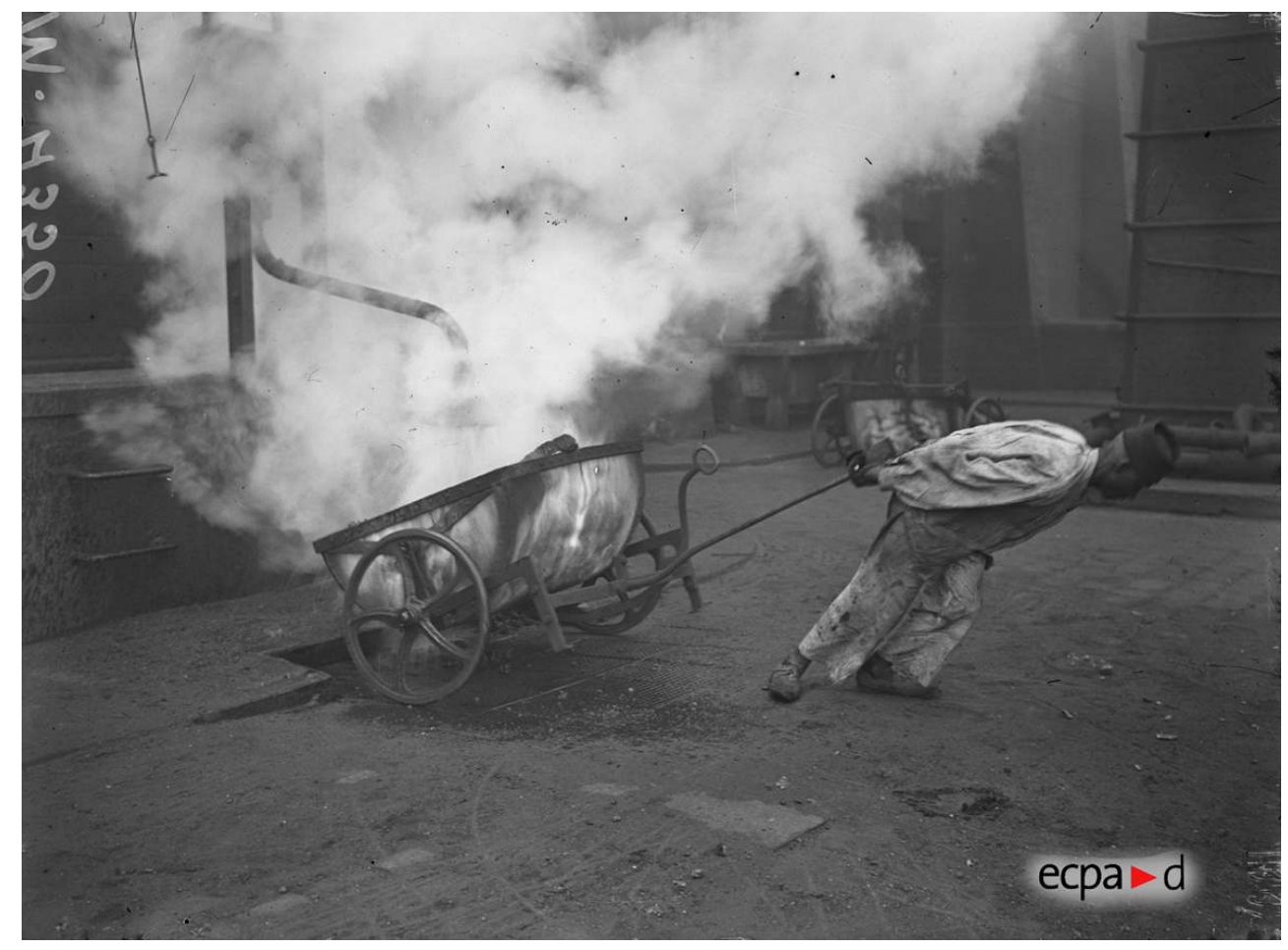

USINE dE gAZ À CLICHY (HAUTS-DE-SEINE). SORTIE DU COKE DANS DES VOITURES SPÉCIALES. PHOT. MOREAU, ALBERT. (C) ECPAD, SEPTEMBRE 1917, RÉF. SPA 220 M 4350.

Comme le souligne Toshikatsu Nakajima ${ }^{35}$, l'augmentation du recours à l'électricité ne signifie pas que l'on modifie les systèmes de transmission. Les machines à commande individuelle ne concernent que le petit usinage. Les autres restent dépendantes des grands systèmes de courroies qui parcourent les ateliers, telles des forêts de lianes (voir fig. $\mathbf{n}^{\circ} \mathbf{4}$ ), de sorte que leur disposition ne peut guère se modifier, ce qui n'est pas fait pour fluidifier l'enchaînement des opérations de production d'une part ni s'adapter rapidement à la variété des commandes d'autre part.

41 Le secteur français de la machine-outil est de tradition ancienne et a prospéré à Paris sous le Second Empire. Decoster, Pinchart-Deny et Bouhey, constructeurs parisiens dont plusieurs exemples de réalisations sont visibles dans les reportages des photographes militaires, existent depuis le milieu du XIX ${ }^{\mathrm{e}}$ siècle. Decoster fabrique des raboteuses et des machines à tailler les engrenages à Montparnasse. Pinchart-Deny (fig. $\mathbf{n}^{\circ}{ }^{\mathbf{2 3}}$ ) a ses ateliers rue Saint-Sabin, dans le $\mathrm{XI}^{\mathrm{e}}$ arrondissement. Bouhey (fig. $\mathbf{n}^{\circ} \mathbf{2 4}$ ), qui devient ensuite la Société d'outillage mécanique et d'usinage d'artillerie (SOMUA), est implanté avenue Daumesnil et à Saint-Ouen. Le secteur est cependant déjà fortement concurrencé avantguerre par les importations américaines et allemandes. En 1913, il occupe 3000 ouvriers pour une production de 8000 tonnes de machines; la même année, 24000 tonnes de machines sont importées et pourvoient aux trois-quarts des besoins de l'industrie française. En 1914, alors qu'il faudrait développer le secteur français pour pallier l'arrêt des importations en provenance d'Allemagne, les fabricants de machines-outils sont au contraire requis pour usiner dans l'urgence des obus et des bombes et ne peuvent plus se consacrer à leur activité traditionnelle. Avec la création du Comité interministériel de l'outillage mécanique, le gouvernement tente de faire repartir la production mais il 
faudrait pour cela y consacrer une partie de la main-d'œuvre disponible, ce qui ne fait pas l'affaire des militaires. Par ailleurs, le métal est contingenté. On va donc accentuer le recours à l'importation de machines anglaises et américaines, sur lesquelles l'autorité militaire exerce en outre un contrôle de répartition et d'affectation en fonction des besoins les plus urgents. Au cours du conflit, les livraisons de l'étranger bondissent (274 000 tonnes de machines importées de 1915 à 1921) et le secteur de la machine-outil n'emploie pas plus de personnel après la guerre qu'avant ${ }^{36}$. Les clichés pris par les opérateurs de la SPCA montrent plusieurs machines anglaises et américaines (Davy-Bros Ltd à Sheffield par exemple, RD Wood \& Co à Philadelphie ou Diamond Machine Co à Providence) en action dans les usines d'armement françaises de Saint-Étienne et de SaintChamond. Pendant ce temps, l'Allemagne, qui ne peut compter que sur ses propres fabrications (et sur le fer lorrain...), continue à développer ce secteur industriel et voit progresser le nombre de ses constructeurs. Après le conflit, de nombreuses machines allemandes seront livrées à la France au titre des dommages de guerre, ce qui ne contribuera pas au relèvement du secteur français de la machine-outil.

\section{Figure 23}

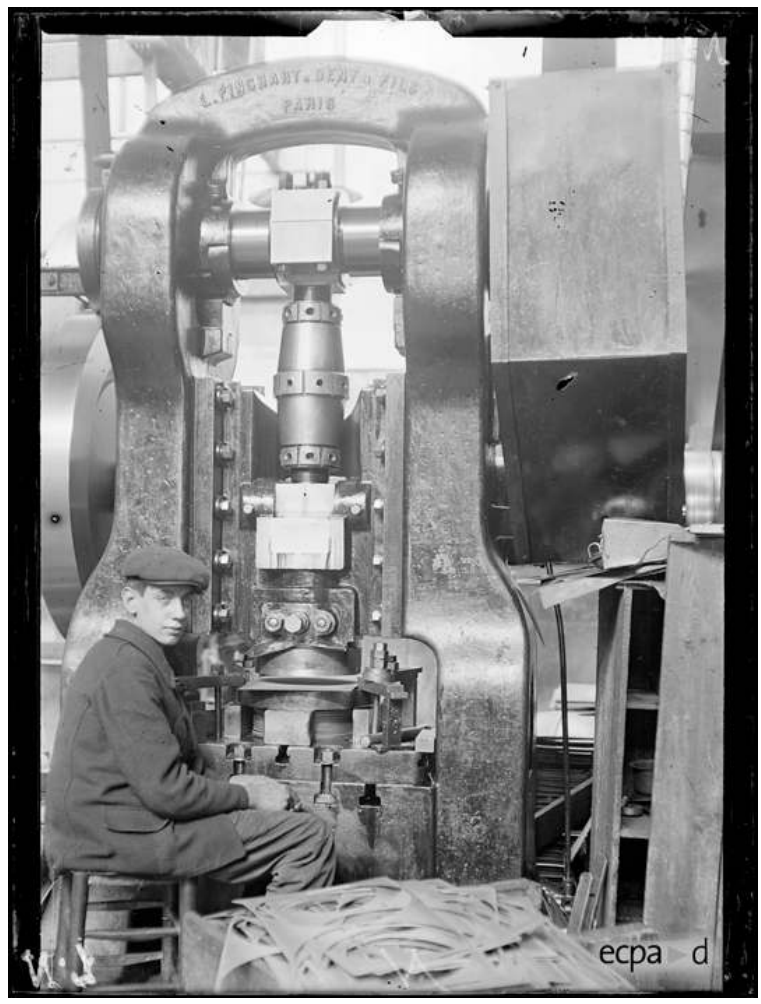

PARIS, ATELIER DUPEYRON. EMBOUTISSAgE DES CASQUES ADRIAN SUR UNE PRESSE PINCHART-DENY. PHOT. PANSIER, PIERRE. (C) ECPAD, JUIN 1916, RÉF. SPA 2 N 9. 


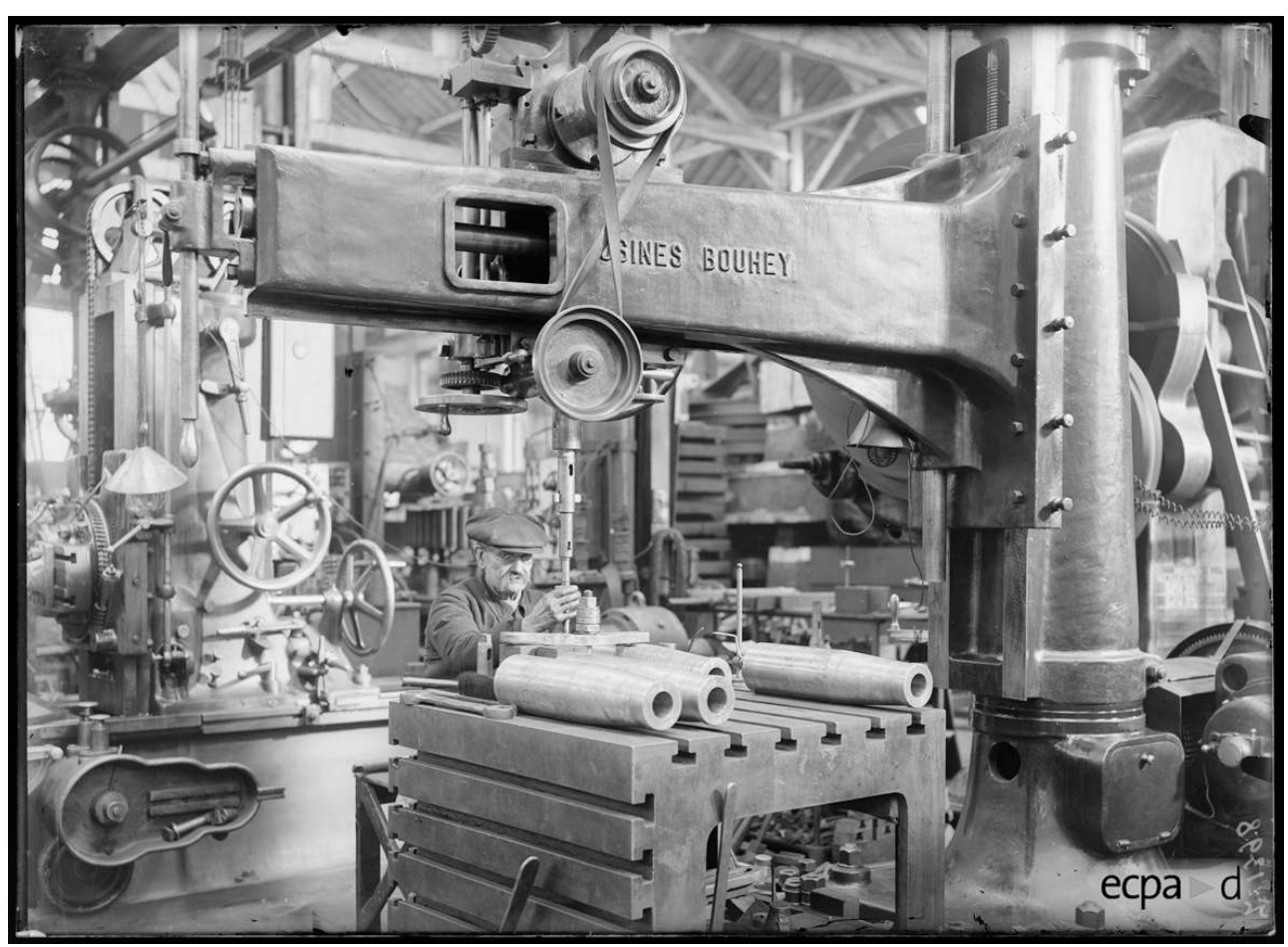

SAINT-ÉtienNe (LOIRE). SOCIÉTÉ deS MOTEURS LEFLAIVE ET CIE. ALÉSAgE AVEC UNE MACHINE dE MARQUE BOUHEY.

PHOT. AUBERT, ISIDORE. @ ECPAD, JANVIER 1916, RÉF. SPA 25 Z 1398.

On assiste pendant les quatre années de guerre à un début d'harmonisation des productions chez les sous-traitants qui doivent fournir aux industriels des roulements, magnétos, projecteurs, bougies et pièces diverses plus ou moins normés. Ils échangent des informations par le biais du Bulletin des usines de guerre, créé à l'initiative d'Albert Thomas, dans lequel sont publiés des articles sur l'économie, le commerce, la législation du travail mais également des rubriques techniques sur les procédés de fabrication. Le processus d'harmonisation est encouragé par le ministère du Commerce et de l'Industrie qui met en place, par un décret du 10 juin 1918, la Commission permanente de standardisation, ancêtre de l'Association française de normalisation (AFNOR). Par ailleurs, les usines tentent de rationaliser leur production. La question demeure pendante de savoir s'il s'agit d'un véritable mouvement de taylorisation ou de l'emprunt de quelques méthodes d'organisation vues sur des chaînes de montage étrangères, simplement transposées sur la production locale. Quelques entreprises possèdent avant 1914 un véritable bureau d'étude des méthodes de travail mais le processus entamé est plutôt freiné par l'arrivée de la guerre : en effet, la pertinence des expériences acquises avant le conflit devient caduque car, du jour au lendemain, on ne fabrique plus les mêmes produits. L'usine doit faire face à plusieurs grandes mutations :

- elle n'a plus les mêmes objectifs (passage d'une fabrication spécifique à des produits militaires),

- elle ne dispose plus de la même main-d'œuvre (femmes, déqualification),

- elle ne s'adresse plus au même marché (passage de la commande privée à la commande d'État), 
- mais elle opère dans de nouvelles conditions morales (consensus des masses ouvrières autour de l'idée de la patrie à défendre, au-delà des conflits au sein de l'entreprise, du moins dans un premier temps) susceptible de favoriser les changements.

La nécessité d'abandonner une spécialisation et de se reconvertir dans l'urgence à d'autres procédés, sans référence au passé, oblige à l'innovation. Elle s'opère toutefois avec d'autant plus de difficulté que la conception de l'objet à produire (obus, pièces de fusil, etc.) se fait ailleurs, dans un bureau d'études distant qui ne peut directement influer sur l'organisation de la production ${ }^{37}$. Celle-ci démarre dans une certaine improvisation et doit être ultérieurement révisée puis changée au fil des commandes successives de produits différents. Dans ces conditions, il est difficile d'appliquer entièrement les principes du taylorisme, du moins au début. Une photographie prise à l'arsenal de Brest (fig. ${ }^{\circ} 25$ ) montre cependant une certaine organisation en chaîne : des obus arrivent d'un atelier voisin sur un plan incliné devant deux femmes qui les dirigent ensuite vers une table disposée perpendiculairement, où une double rangée d'ouvrières semble chacune effectuer une opération de vérification. La guerre accélère des processus qui étaient déjà en germe localement, notamment chez certains constructeurs automobiles auxquels l'obligation de fabriquer des obus en grande série donne des idées sur la future réorganisation de leur chaine de production spécifique. Cependant, dans l'esprit tayloriste ou fordiste, l'augmentation du rendement de l'ouvrier doit s'accompagner de celle des salaires et d'une diminution du temps de travail, ce qui n'est pas le cas pendant le conflit, le but premier de la rationalisation étant une production poussée au maximum.

Figure 25

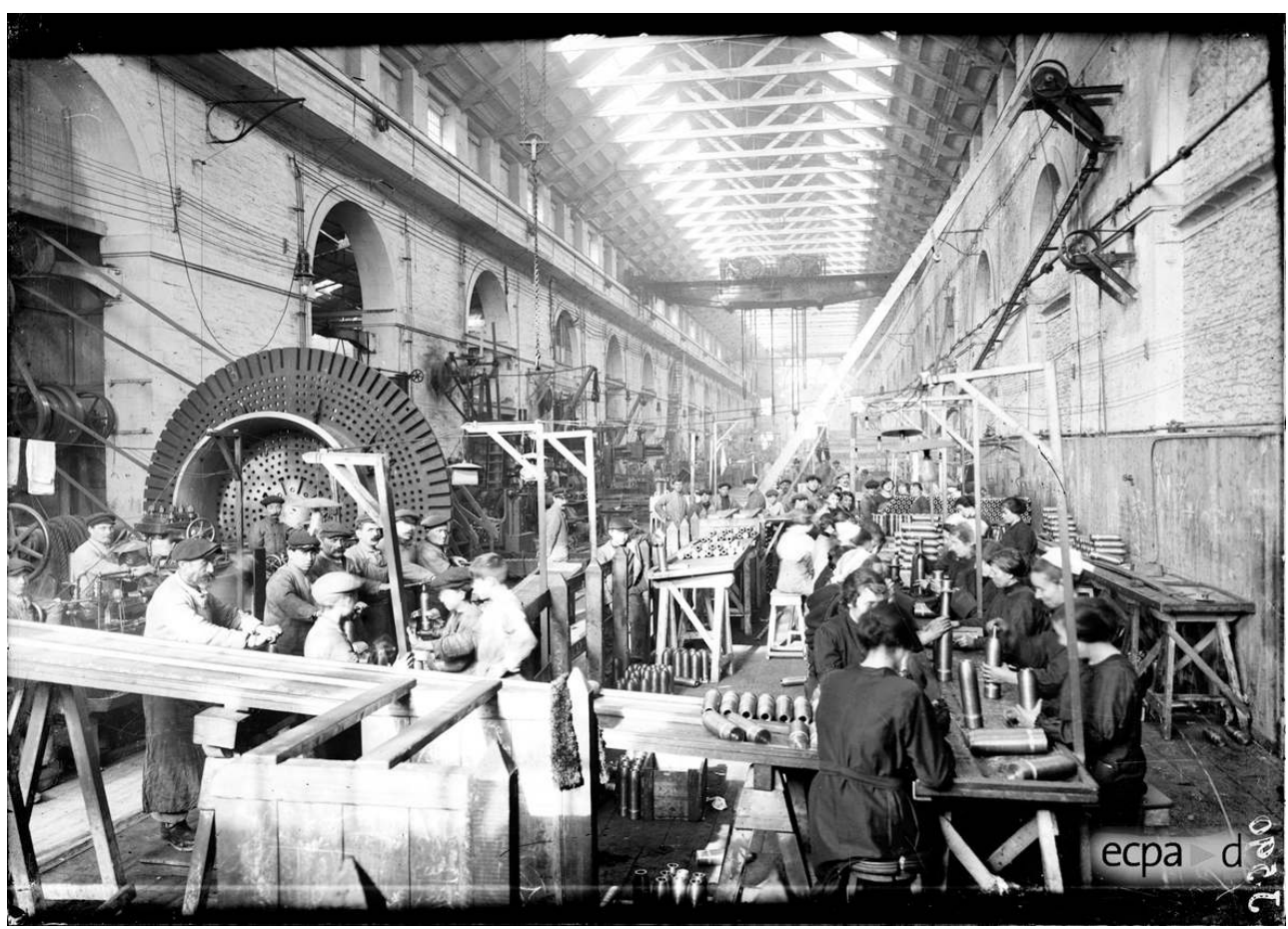

ARSENAL DE BREST (FINISTÈre). ATELIER DE CONTRÔLE DES OBUS APRÈS LA fINITION.

PHOT. DANgEREUX, GEORgES. (C) ECPAD, MARS 1916, RÉF. SPA 7 J 590.

L'obligation d'employer une main-d'œuvre féminine va par ailleurs faire progresser les processus au sein des usines sur les plans de la manutention et du contrôle de la qualité. 
Comme il est nécessaire d'économiser la force musculaire des ouvrières pour la consacrer le plus possible à l'usinage, l'État incite les industriels, dont certains sont réticents, à développer des procédés d'aide à la manipulation des pièces lourdes. Dans un rapport présenté au Sénat le 20 novembre 1916, Paul Strauss préconise « le recours aux engins de transport, ponts roulants, monorails suspendus, chariots légers à traction mécanique, électrique, plans inclinés, etc. ${ }^{38}$ ». Il cite notamment les efforts entrepris sur ce plan par l'entreprise Gobron, à Meudon, où les femmes sont employées à l'usinage d'obus de $270 \mathrm{~mm}$. Quant à la déqualification de la main-d'œuvre entraînée par l'augmentation du pourcentage d'éléments féminins, encore peu habitués au travail de la métallurgie, elle va avoir paradoxalement l'effet de mettre l'accent sur le contrôle de la qualité. En effet, ce dernier est, avant la guerre, en partie assuré par les ouvriers qualifiés mais ils sont partis au front et ne sont plus assez nombreux dans les usines, malgré le retour organisé d'une partie d'entre eux. Il est donc nécessaire de pallier leur absence par la création de cette étape de la production, le contrôle, qui est assuré par des femmes.

Bien qu'il existe quelques tentatives de formation professionnelle en amont dans les écoles pratiques d'industrie ou les écoles d'Arts et Métiers, l'essentiel de la formation de la main-d'œuvre féminine s'effectue au sein des entreprises. Certains établissements, tels l'arsenal de Puteaux, mettent en œuvre des parcours professionnels : après l'acquisition d'une première expérience dans l'usinage sous la direction d'un outilleur, les femmes « peuvent demander à passer l'essai de tourneur ou d'ajusteur professionnel comme les hommes ${ }^{39} »$.

\section{Du pâté en conserve au canon de $340 \mathrm{~mm}$ : l'industrie en province}

\section{Nourrir et vêtir le soldat}

En janvier 1916, le photographe Gabriel Boussuge entreprend en province une grande tournée de reportages photographiques presque exclusivement consacrée à l'industrie. Il visite des établissements qui se consacrent en partie à des fabrications militaires mais il s'intéresse aussi à des productions civiles qui illustrent le savoir-faire traditionnel français. Avant de quitter Paris, il se rend à l'exposition de «La Cité reconstituée » où sont présentées des habitations provisoires destinées aux régions qui seront à reconstruire. Ces édifices sont les ancêtres de nos modernes préfabriqués. L'entreprise Cohier, de Dourdan, propose par exemple sur un panonceau des constructions brevetées " composées de parties interchangeables complètement, en ciment armé pour l'extérieur, en plâtre et liège pour l'intérieur... d'un montage rapide et facile », déclinées en diverses dimensions et apparences. Les Constructions ogivales Farcot, dont les ateliers sont à Honfleur, commercialisent des hangars métalliques et arborent une pancarte vantant un nouveau modèle, «l'habitation à soi - livrée en 10 jours ». Traversant ensuite l'actuelle région Centre, Boussuge visite à Orléans l'usine Rivière qui fabrique du matériel agricole moderne, locomobiles à vapeur, batteuses et presses à foin. Pour promouvoir la mécanisation, le ministre du Commerce Étienne Clementel a mis sur pied un service de la motoculture. À Châteauroux, une manufacture de tabac travaille pour les troupes. Faisant escale à Limoges, l'opérateur photographie aux ateliers Haviland, entreprise emblématique des arts de la table, toutes les étapes de la fabrication de la vaisselle fine: coulage, calibrage, modelage de pièces ouvragées, peinture des décors, émaillage, 
retouche, dorure, cuisson et emballage de la production dont une partie est exportée aux États-Unis. Décrivant ensuite une grande boucle vers l'Anjou, la Vendée, le Sud-Ouest, le Massif central, la région lyonnaise et l'Isère, il alterne les reportages dans des établissements travaillant pour l'armée - coutellerie de Thiers où sont fabriquées les baïonnettes (fig. $\mathbf{n}^{\circ} \mathbf{2 6}$ ) - et des entreprises fabriquant des produits typiquement français (pastilles Vichy, dentelle du Puy, tapis d'Aubusson, ganterie de luxe grenobloise, chapellerie de Caussade, dont les canotiers sont mis en caisses pour être exportés vers Gibraltar et l'Afrique du Nord). Il importe de montrer à l'arrière et aux pays importateurs de produits français que, bien que les moyens de l'industrie nationale soient en grande partie consacrés à la guerre, les activités traditionnelles ne sont pas délaissées et que les marchés intérieurs et internationaux peuvent être correctement approvisionnés.

Figure 26

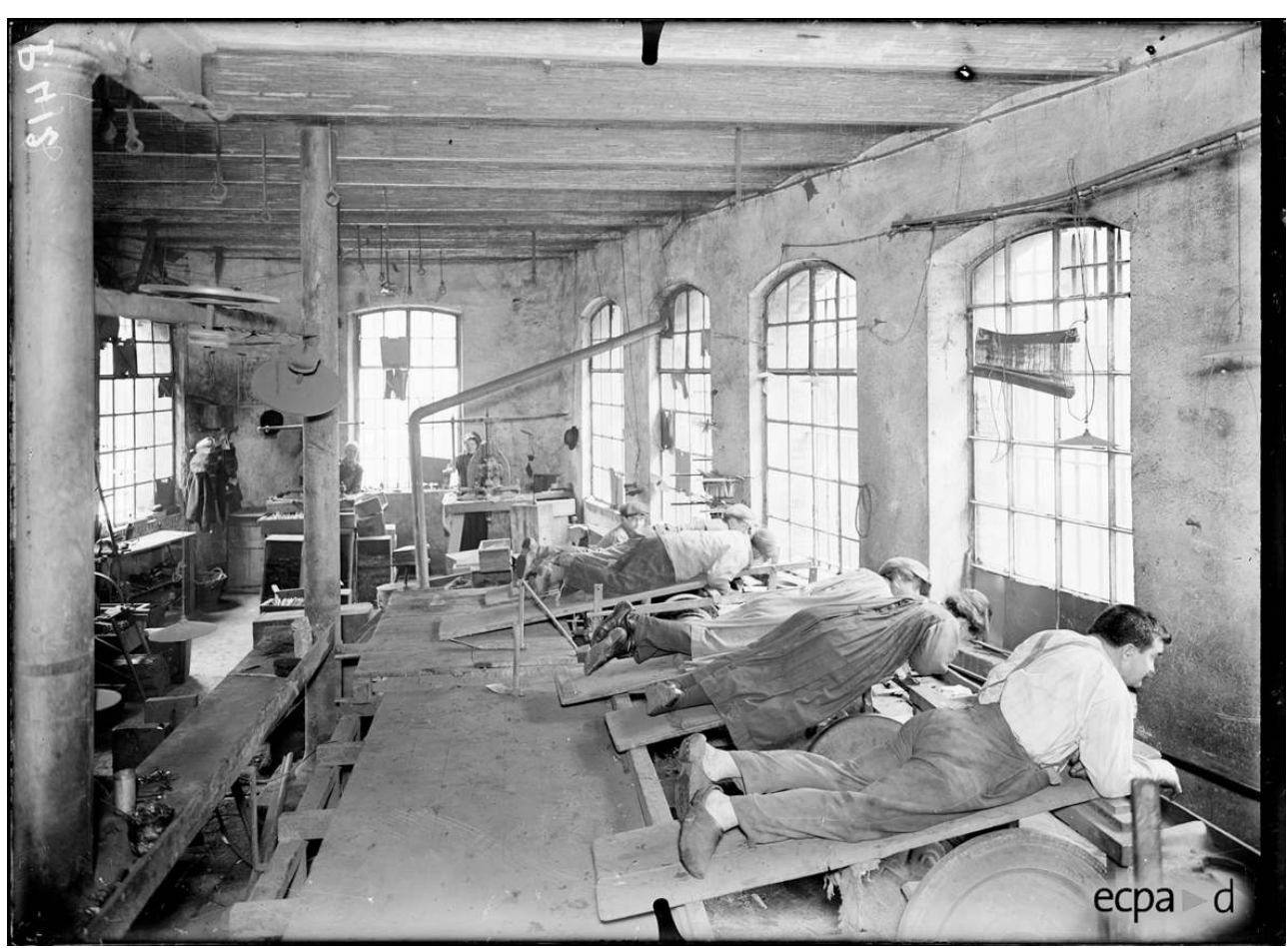

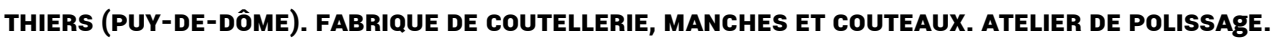
PHOT. BOUSSUgE, GABRIEL. @ ECPAD, AVRIL 1916, RÉF. SPA 38 P 412.

Le secteur agro-alimentaire n'est pas oublié, étant donné son importance pour l'approvisionnement des troupes. Le chocolat, produit emblématique de la gastronomie mais également denrée couramment consommée dans les tranchées ${ }^{40}$, fait l'objet d'un reportage chez Poulain, à Blois. Gabriel Boussuge visite ensuite plusieurs usines de conserves. Dans l'Aveyron, aux conserveries Raynal et Roquelaure de Capdenac, rien n'est encore mécanisé et le remplissage des boîtes de charcuterie se fait à la main : sur un cliché, on distingue les ouvrières, debout autour de tables en bois, qui pèsent d'abord les boîtes métalliques vides, puisent ensuite le pâté dans de grandes bassines, le tassent dans les boîtes, raclent le surplus en se servant du couvercle comme d'une spatule et les déposent sur un plateau. Il en va de même aux conserveries Tyssonneau, à Bordeaux, où on peut voir dans un atelier artisanal un boucher découper les viandes, deux femmes debout effectuant à la main la trituration d'un pâté dans une auge, et deux autres, assises, 
remplissant avec la préparation des boîtes simplement posées sur leur tablier ; en arrièreplan se distinguent des hachoirs actionnés par des courroies (fig. $\mathbf{n}^{\circ} \mathbf{2 7}$ ).

Figure 27

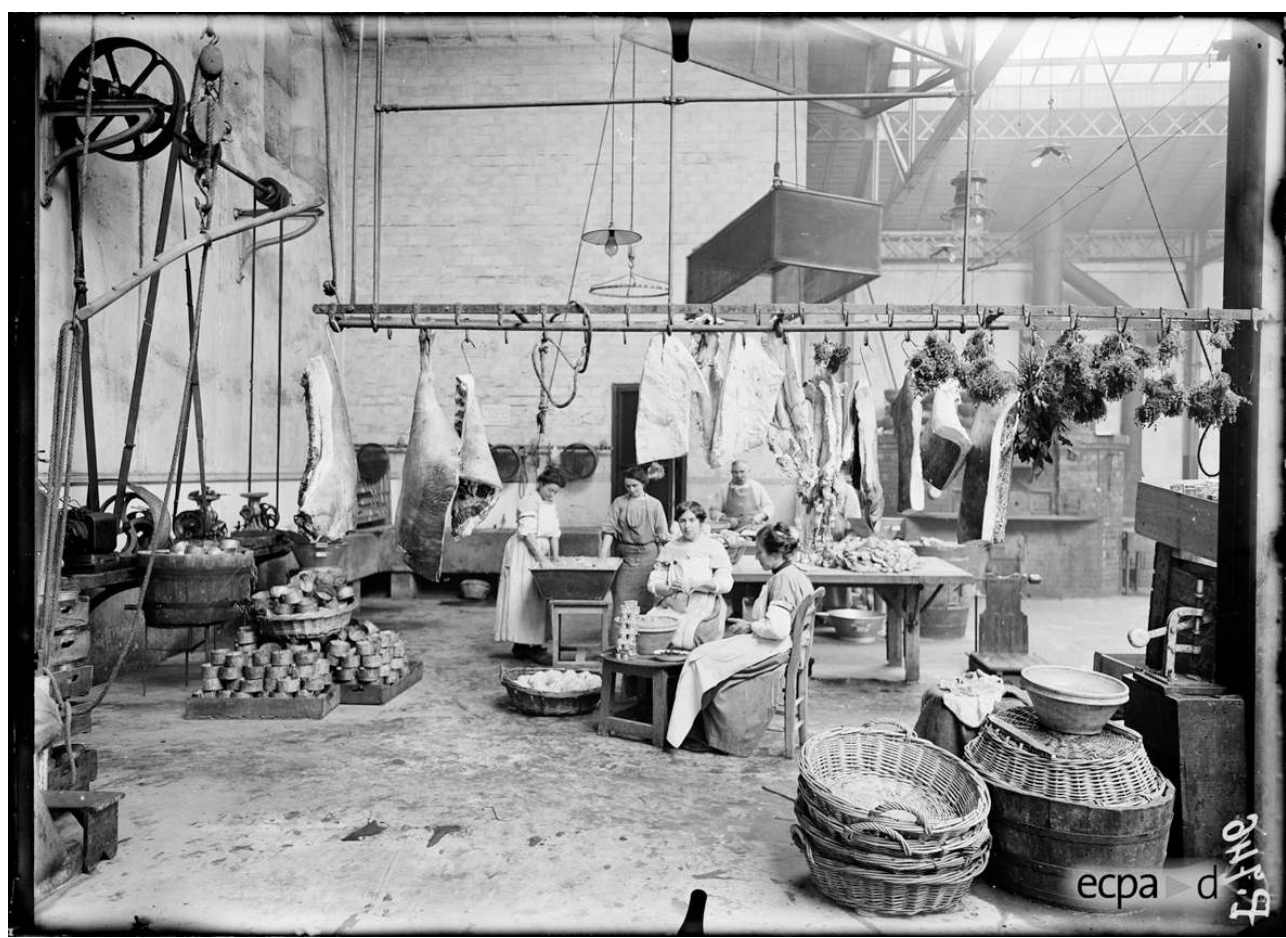

BORDEAUX (GIRONDE). LA FABRIQUE DE CONSERVES TYSSONNEAU : LA PRÉPARATION DES CONSERVES DE VIANDES.

PHOT. BOUSSUgE, GABRIEL. @ ECPAD, DÉCEMBRE 1916, RÉF. SPA 71 P 746.

Aux usines Amieux de Nantes, visitées en janvier 1917 par un autre opérateur de la SPA, Maurice Boulay, la production semble plus importante mais la mécanisation ne parait pas plus avancée : on y voit des femmes remplissant les boîtes en fer blanc à partir de grandes terrines de grès pendant qu'un ouvrier découpe du poulet au bout de la table. Les femmes portent ensuite à bout de bras vers le sertissage les plateaux alourdis d'une vingtaine de boîtes pleines, sans même l'aide d'un chariot. Les étiquettes sont collées à la main. De plus, à Capdenac, les contenants sont fabriqués sur place dans un atelier où s'effectuent la découpe des feuilles métalliques, la mise en forme, la soudure et le sertissage. Chez d'autres industriels, la fabrication des boîtes vides se fait sur un site dédié, comme chez Saupiquet à Quimper, mais qui appartient à l'entreprise. Cette dernière livre à l'armée au cours de l'exercice 1914-1915 près de 6,8 millions de boîtes, soit l'équivalent de 10 millions de francs de l'époque ${ }^{41}$. L'activité est parfois freinée par le manque de fer blanc, notamment pour les entreprises qui ne bénéficient pas de marchés avec l'armée. Les responsables s'en plaignent auprès de l'administration, arguant du fait que, s'ils ne livrent pas directement l'intendance, ils contribuent à l'approvisionnement du soldat au front par l'intermédiaire des colis expédiés par les familles et les œuvres de bienfaisance.

Gabriel Boussuge porte également de l'intérêt au secteur viticole, visitant le négociant en vins Mestrezat où un officier du $139^{\mathrm{e}}$ régiment d'infanterie procède à une dégustation avant achat. Peut-être est-il chargé de prospecter avant de passer commande pour l'armée ? Le secteur sucrier fait aussi l'objet de reportages : en effet, de nombreuses terres 
à betterave et les raffineries qui s'y rapportent sont situées dans les territoires occupés du Nord et de l'Est, et les autres régions betteravières françaises sont appelées à les remplacer. Sur les clichés de Boussuge, on voit des Allemands effectuant la manutention des tubercules. En effet, les prisonniers constituent une main-d'œuvre bon marché, moins chère que les travailleurs que l'on fait venir des colonies. On y recourt dans l'industrie mais aussi dans l'agriculture, les collectivités locales, dans les ports pour la manutention, etc. Certains prisonniers restent en France jusqu'en 1920, le secteur productif n'étant pas pressé de s'en séparer.

50 L'industrie textile, en comparaison du secteur agro-alimentaire, parait très moderne, comme le montre la fabrique de drap militaire de Châteauroux (fig. $\mathbf{n}^{\circ} \mathbf{2 8}$ ). D’énormes machines à laver la laine sont alignées dans un atelier et une cinquantaine de métiers à tisser tournent comme des horloges sous une grande verrière. L'opérateur profite de la dimension des bâtiments et de la qualité de l'éclairage naturel pour réaliser des clichés en vue plongeante et des prises de vue accentuant la perspective, qui mettent en valeur les machines et donnent une impression de puissance. Le secteur textile travaille énormément pour l'armée dont les besoins sont considérables: pour le seul hiver 1917-1918, elle commande pas moins de 10 millions de chemises et 20 millions de paires de chaussettes ${ }^{42}$.

\section{Figure 28}

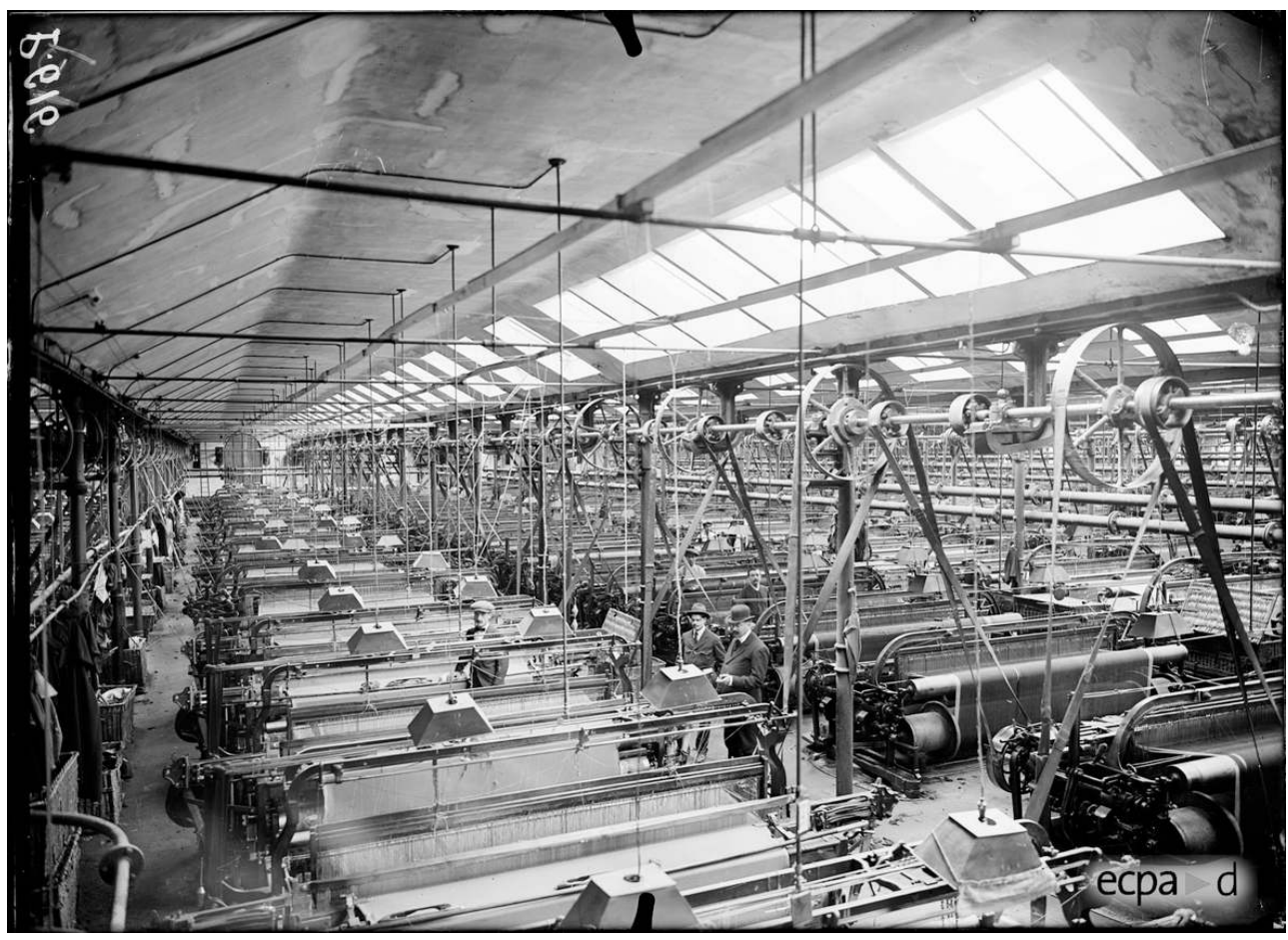

ChÂTEAUROUX (INDRE). MANUfACTURE DE DRAP dE TROUPE BALSAN. LE TISSAge.

PHOT. BOUSSUgE, GABRIEL. () ECPAD, NOVEMBRE1916, RÉF. SPA 58 P 616.

\section{Sidérurgie et industrie chimique}

51 Les hauts-fourneaux et les usines du Nord et de la Lorraine étant aux mains de l'ennemi et forcés de travailler pour l'industrie allemande, avant d'être en grande partie détruits en 1918, les bassins du Centre, du Creusot et de Saint-Étienne, qui ne sont pas touchés, 
prennent le relais. Malgré les difficultés de transport, ils sont approvisionnés en matières premières par l'Angleterre puis par les États-Unis. Le Comité des forges, via un bureau à Londres, coordonne le ravitaillement en fonte, acier, minerai d'hématite et produits réfractaires. L'opérateur Isidore Aubert, au cours d'un voyage en province, s'intéresse plus particulièrement aux aciéries de Saint-Chamond dont la raison sociale exacte est "Compagnie des forges et aciéries de la marine et d'Homécourt». On y fabrique des pièces d'artillerie de gros calibre sur voie ferrée. La société, qui produit, comme son nom l'indique, des fournitures pour l'industrie lourde et la marine, est aussi spécialiste du rail et construit des locotracteurs de chantier pour voie de 0,63 m. Elle est également productrice du char Saint-Chamond. L'entreprise deviendra ultérieurement CreusotLoire. Pendant la guerre, elle se trouve à la tête d'un groupe de fabrication qui, comme celui du Creusot, a été formé dès septembre 1914 pour fournir des canons. Au cours de son reportage, le photographe met en œuvre tout son art afin de rendre compte de la puissance industrielle mise au service de l'État par les industriels de la Loire: dans l'atmosphère sombre des ateliers de fonderie, il profite de la lueur des coulées en fusion et de l'incandescence des barres d'acier chauffées à blanc pour réaliser des vues en clairobscur (fig. $\mathbf{n}^{\circ} \mathbf{2 9}$ ). Dans les ateliers d'usinage, il utilise les surfaces lisses et brillantes du métal pour capter la lumière et mettre en valeur la matière des pièces et des machines qu'il photographie souvent en contre-plongée, magnifiant ainsi la dimension des gigantesques presses et des tours. Depuis les ponts roulants, il réalise des vues plongeantes sur un canon de $340 \mathrm{~mm}$ et l'affût-truck qui portera la pièce (fig. $\mathbf{n}^{\circ} \mathbf{3 0}$ ). Un an plus tard, en juin 1917, le caméraman Georges Daret utilise les mêmes techniques pour filmer ces fabrications. Juché sur un pont roulant avec sa caméra, il réalise des travellings sur les alignements de canons qui s'étendent à perte de vue dans un atelier puis, redescendu près des énormes tours sur lesquels sont fixés les tubes en cours d'usinage, il en scrute l'intérieur pour montrer le rayage, le rétrécissement de la perspective créant un effet de loupe. La trempe des grosses pièces est l'occasion de filmer, en plan large et à bonne distance, les geysers de vapeur qui s'échappent d'un bassin à l'extérieur ${ }^{43}$. 
Figure 29

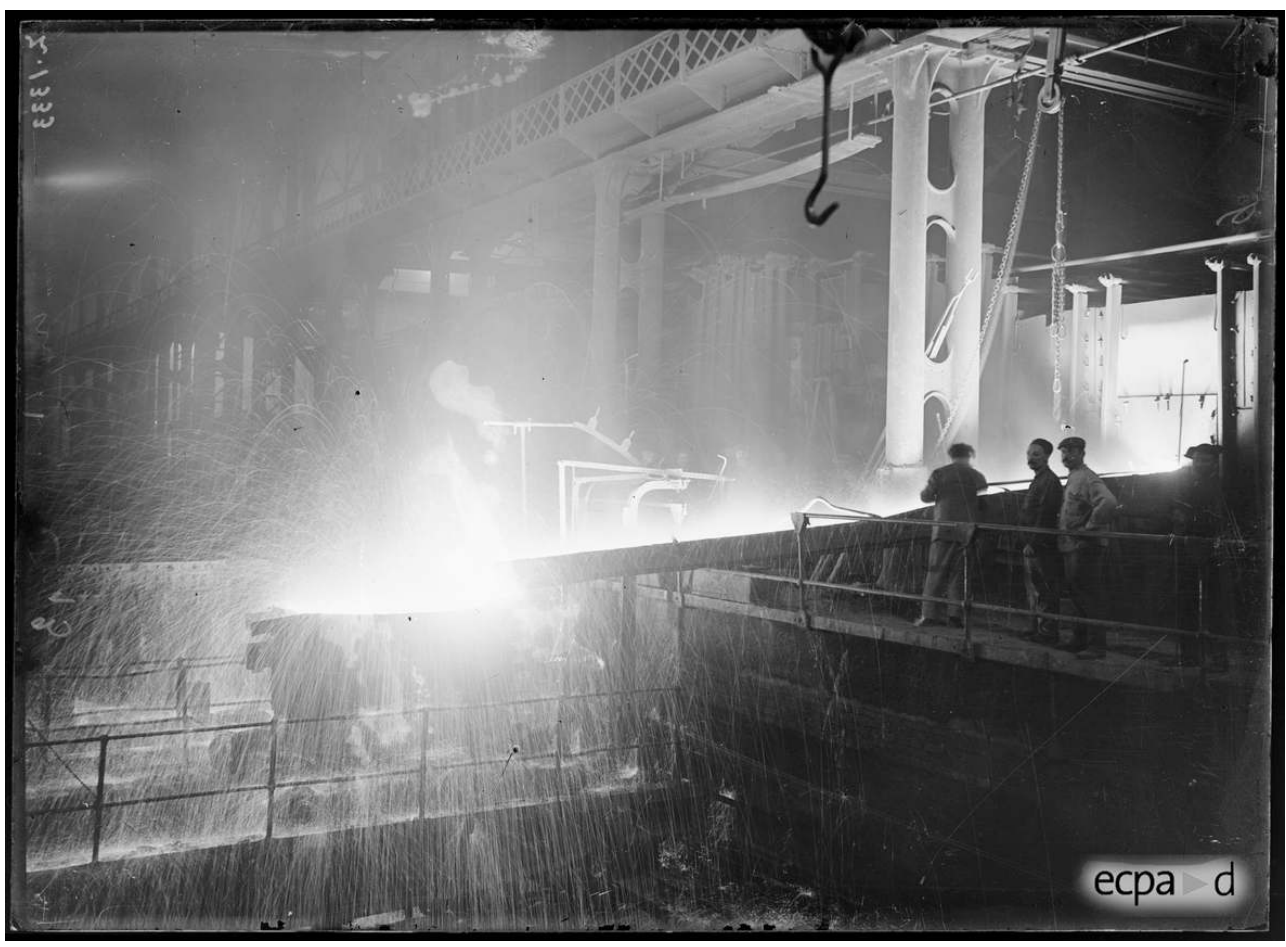

ACIÉRIES DE SAINT-CHAMOND (LOIRE). DANS LES LINgOTIÈRES.

PHOT. AUBERT, ISIDORE. () ECPAD, JANVIER 1916, RÉF. SPA 25 Z 1333.

Figure 30

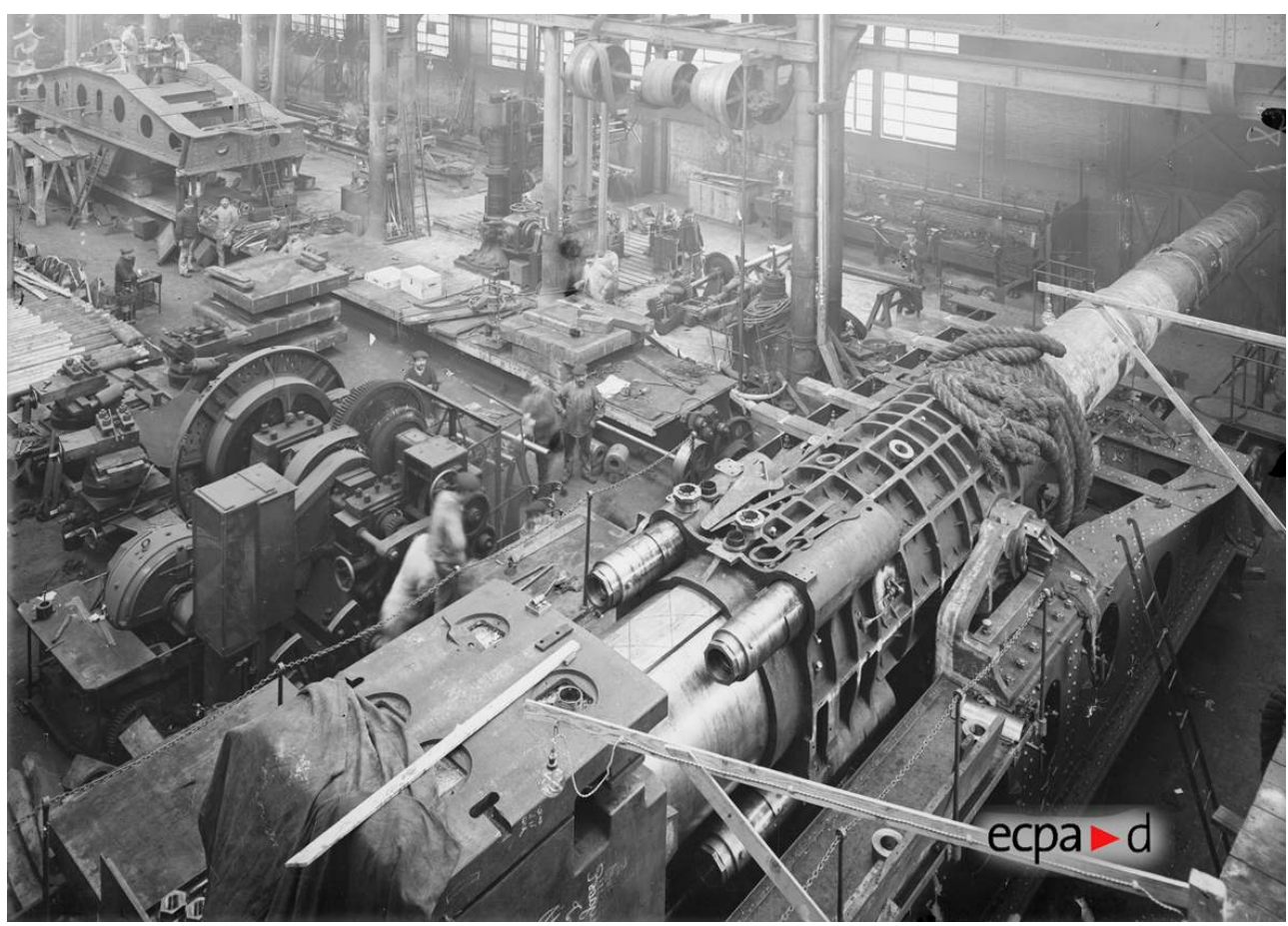

ACIÉRIES DE SAINT-CHAMOND (LOIRE). CANON DE 340 MM EN fiNITION.

PHOT. AUBERT, ISIDORE. @ ECPAD, JANVIER 1916, RÉF. SPA 25 Z 1503. 
Passant par Saint-Étienne, le photographe Isidore Aubert se rend à la manufacture d'armes où il observe les conditions de travail du personnel, qui compte de nombreuses femmes mais aussi des hommes d'un certain âge. Aux forges de la Chaléassière, il semble impressionné par le travail des ouvrières munies de lunettes de protection, qui soudent au chalumeau des ailettes sur des torpilles de crapouillots. Les hommes véhiculent ensuite les munitions sur des brouettes et vont les remplir d'explosifs à la main à l'aide de seaux et d'entonnoirs. Hommes et femmes disposent au sein des ateliers de certaines installations "de confort", telle cette table à réchauffer les aliments sur laquelle est disposée une trentaine de récipients de toutes sortes: traditionnelles gamelles en fer blanc du travailleur mais aussi petits faitouts en terre cuite, bols en faïence et plats en porcelaine; les nouveaux employés apportent leur repas dans la vaisselle dont ils disposent chez eux. Poursuivant vers le sud, il visite les usines chimiques du delta du Rhône: la région produit des matières premières entrant dans la composition des explosifs et des gaz de combat. Aux poudreries de Camargue, il se rend notamment à l'usine d'acide nitrique de Port-Saint-Louis-du-Rhône dont il réalise des vues d'ensemble (fig. $\mathbf{n}^{\circ} \mathbf{3 1}$ ) après avoir photographié les ateliers où sont distillés les produits servant à fabriquer le TNT.

\section{Figure 31}

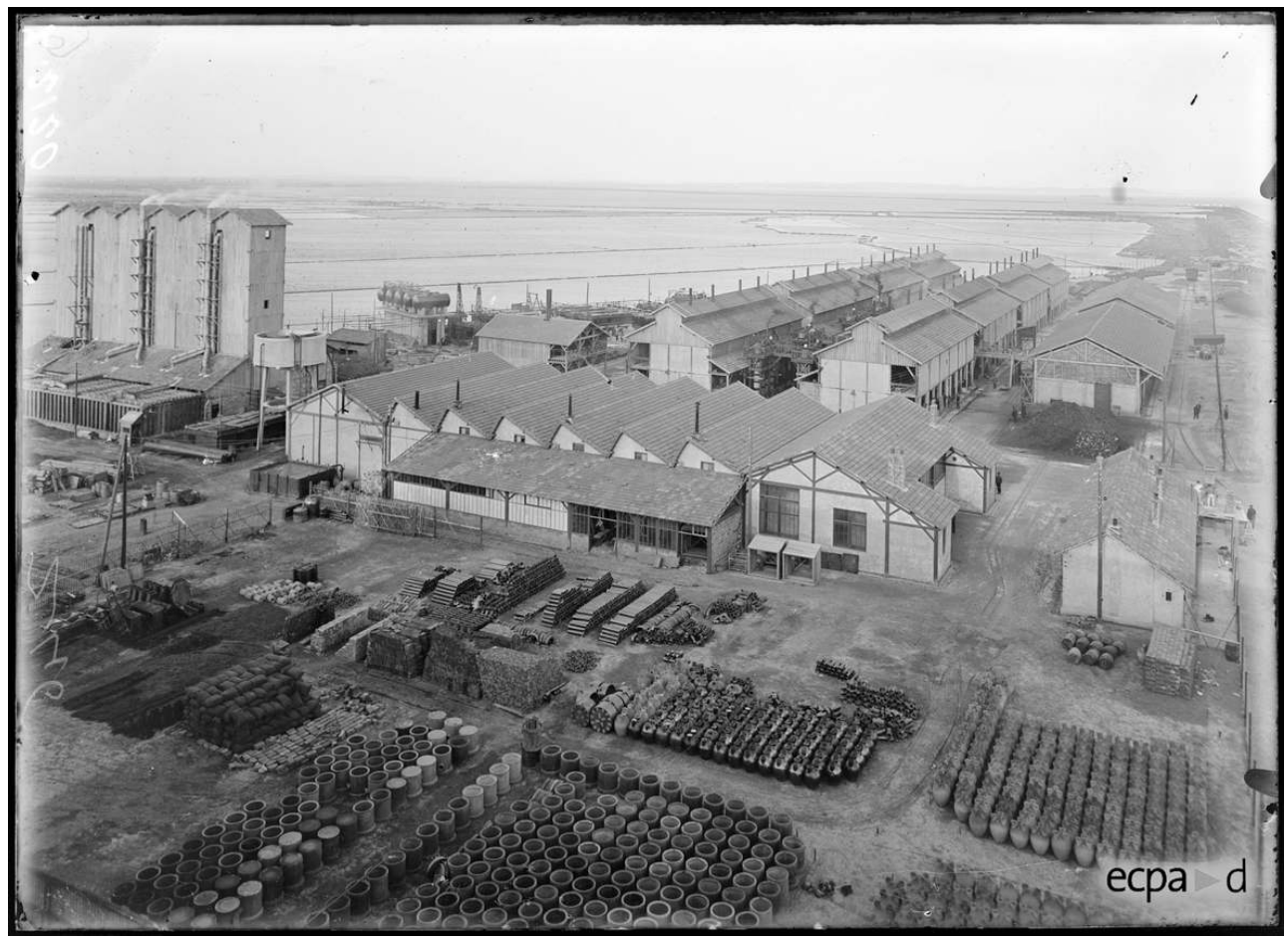

Poudrerie de Port-Saint-Louis-du-Rhône (Bouches-du-Rhône). Ensemble de l'usine à acide nitrique.

PHOT. AUBERT, ISIDORE. (C) ECPAD, AVRIL 1916, RÉF. SPA 38 Z 2120.

On ne peut évoquer l'industrie chimique sans mentionner le rôle qu'a joué dans ce domaine le ministre Louis Loucheur, qui remplace Albert Thomas au ministère de l'Armement en septembre 1917. La France manque de chlore après le début des hostilités du fait de la cessation des importations allemandes. Outre la fabrication du chloroforme pour le service de Santé des armées, la substance est indispensable dans de nombreux domaines industriels (solvants, papeterie) et sanitaires (désinfection) mais aussi comme 
gaz de combat, d'abord sous la simple forme dichlore puis combiné avec diverses molécules qui donnent des formules de plus en plus toxiques, notamment le phosgène. Louis Loucheur et son associé Alexandre Giros possèdent depuis 1916 une usine à Pontde-Claix, dans l'Isère, la Société du chlore liquide, où ce dernier est extrait par électrolyse du sel marin. On y fabrique aussi des gaz de combat (fig. $\mathbf{n}^{\circ} \mathbf{3 2}$ ). Le site sera rattaché ultérieurement à l'entreprise Rhône-Poulenc. Plusieurs autres usines des Alpes, notamment dans le massif de l'Oisans, concourent à la fabrication de produits chimiques, telle la Compagnie universelle d'acétylène et d'électrométallurgie, installée dans la vallée de la Romanche au pied d'une importante chute d'eau. L'énergie hydro-électrique fournie par les différents barrages et conduites forcées construits dans cette vallée fait l'objet d'un document commandité par la direction des Inventions : le film La Houille blanche (réf. 14.18 A 1468) montre les retenues de Rioupéroux, Pierre-Eybesse et des Roberts, dont le caméraman prend des vues en contre-plongée magnifiant la puissance de l'eau et des cascades.

Figure 32

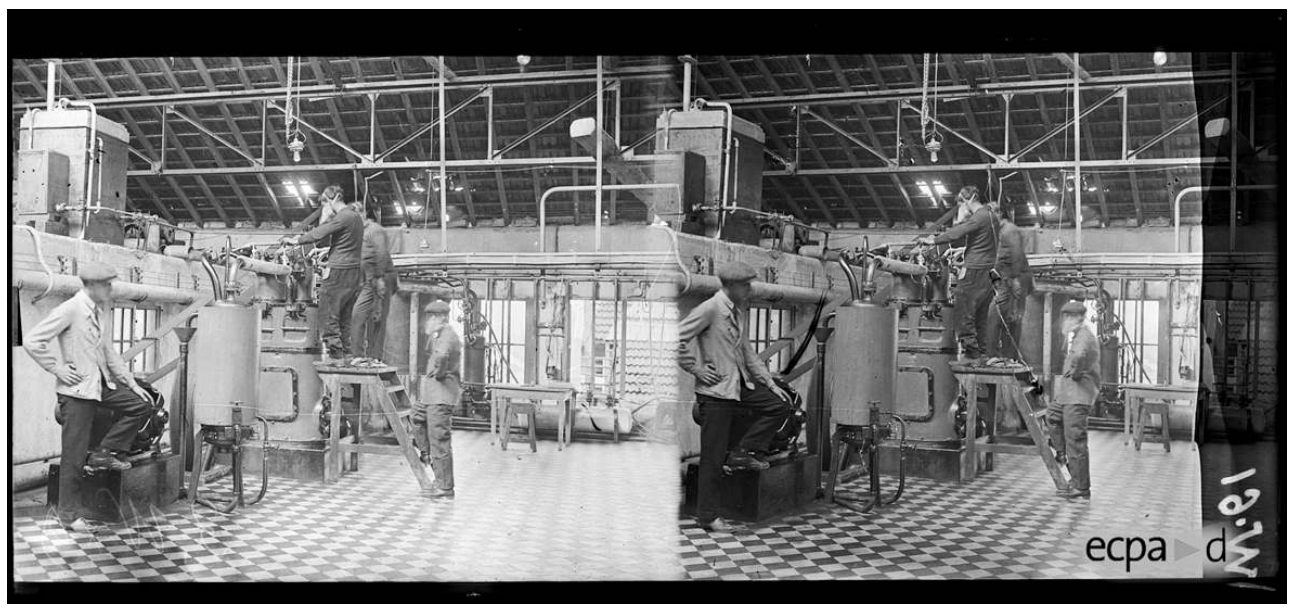

LE PONT-DE-CLAIX (ISÈRE). DANS UNE USINE DE gUERRE, FABRICATION DE gAZ ASPHYXIANTS. VUE STÉRÉOSCOPIQUE.

PHOT. RIDEL, JACQUES. (C) ECPAD, SEPTEMBRE 1916, RÉF. SPA 1 W 61.

Le reporter de la Section photographique et cinématographique de l'armée Maurice Boulay s'intéresse également à l'industrie en temps de guerre, cette fois dans l'ouest de la France. En Touraine et dans les pays de Loire, il visite différentes entreprises sans rapport direct avec les besoins militaires - imprimerie Mame \& Fils, manufacture de chaussures Guerrier et meubles Lefroid à Tours, usine de pâte à papier à Nantes - mais aussi des établissements dont les productions intéressent l'armée. C'est le cas de la tannerie Peltereau à Château-Renault. Le cuir revêt une grande importance à une époque où la traction animale est encore prépondérante ; l'armée en achète beaucoup pour les selles, harnais, brides, rênes, cartouchières, étuis, ceinturons et baudriers. La visite d'usines récemment édifiées est également l'occasion de réaliser des photographies d'architecture mettant en lumière de nouvelles techniques de construction, telle cette charpente en bois lamellé-collé vue à Lyon par Gabriel Boussuge dans un atelier de la société « l'Éclairage électrique » (fig. $\mathbf{n}^{\circ} \mathbf{3 3}$ ). Les éléments de bois cintrés et maintenus ensemble par de la colle et des brides métalliques sont parfaitement visibles, reflétant la technique mise au point en Allemagne en 1890 et brevetée en France au début du siècle. Peut-être les opérateurs prennent-ils ce type de cliché par hasard, en profitant simplement d'une 
ambiance lumineuse nouvelle ; en effet, si les consignes qui leur sont données précisent méticuleusement la façon dont ils doivent photographier les églises, à l'instigation du ministère de l'Instruction et des Beaux-Arts, en vue de leur reconstruction ou dans un but de témoignage, il n'en va pas de même pour les usines et ateliers qui ne font l'objet d'aucun conseil. L'architecture industrielle n'est pas la préoccupation de la Section photographique, sauf si elle est détruite et témoigne ainsi de la barbarie ennemie. Toutefois, il semble que les reporters soient sensibles à cette nouvelle esthétique, multipliant ponctuellement les vues intérieures de ces nouveaux bâtiments.

Figure 33

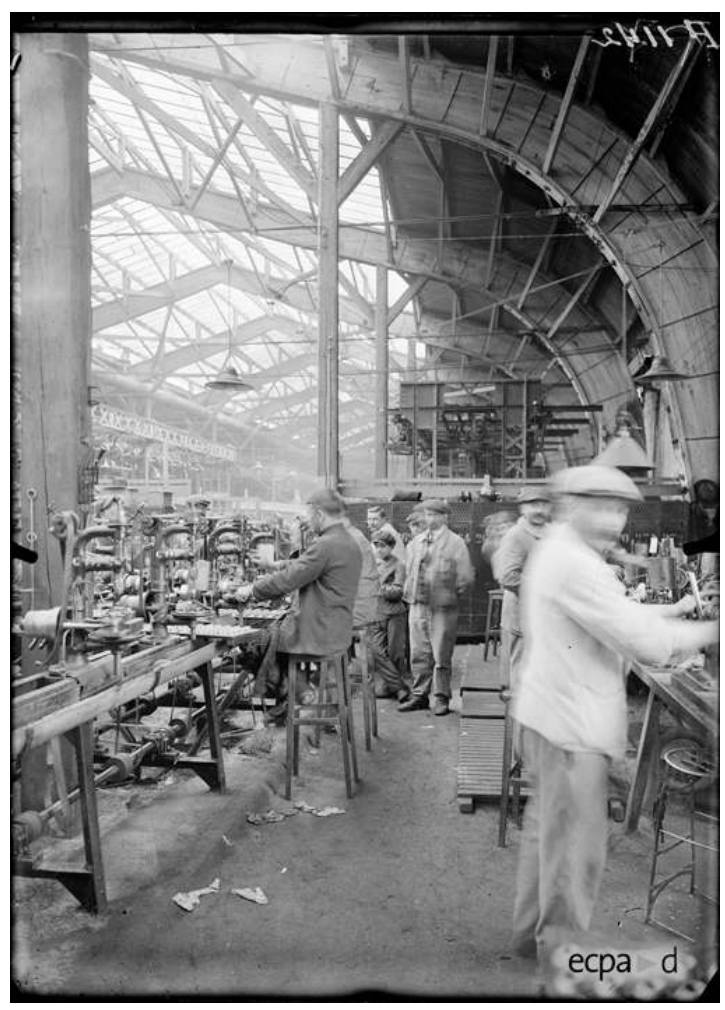

LES ATELIERS de LA SOCIÉTÉ L'ÉCLAIRAgE ÉLECTRIQUE de LYON (RHÔNE).

PHOT. BoussugE, GABRIEL. @ ECPAD, JUIN 1917, RÉF. SPA 95 P 1142.

Enfin, l'industrie semble inspirer les artistes, si l'on en juge par une exposition organisée en juin 1918 à Paris, où sont exposés plusieurs tableaux de Pierre Bracquemond ainsi que ses dessins préparatoires. Il est le fils de Marie Bracquemond, femme peintre impressionniste, et de Félix Bracquemond, graveur. Il immortalise sur ses toiles ce qu'il a observé dans les usines sidérurgiques du Creusot: presses, machines-outils, marteaux pilons, coulées de métal en fusion dans de grands jets d'étincelles et dégagement de fumées, forges, machines à vapeur en action dans de vastes halls, et même la trempe des pièces dans des bassins extérieurs. L'exposition est photographiée à deux reprises, une première fois par Édouard Brissy le $1^{\text {er }}$ juin et une seconde fois par Paul Queste quinze jours plus tard (fig. $\mathbf{n}^{\circ} \mathbf{3 4}$ ). On ne peut que regretter que ce dernier n'ait pas utilisé la technique de l'autochrome pour restituer plus complètement l'effet des tableaux. 
Figure 34

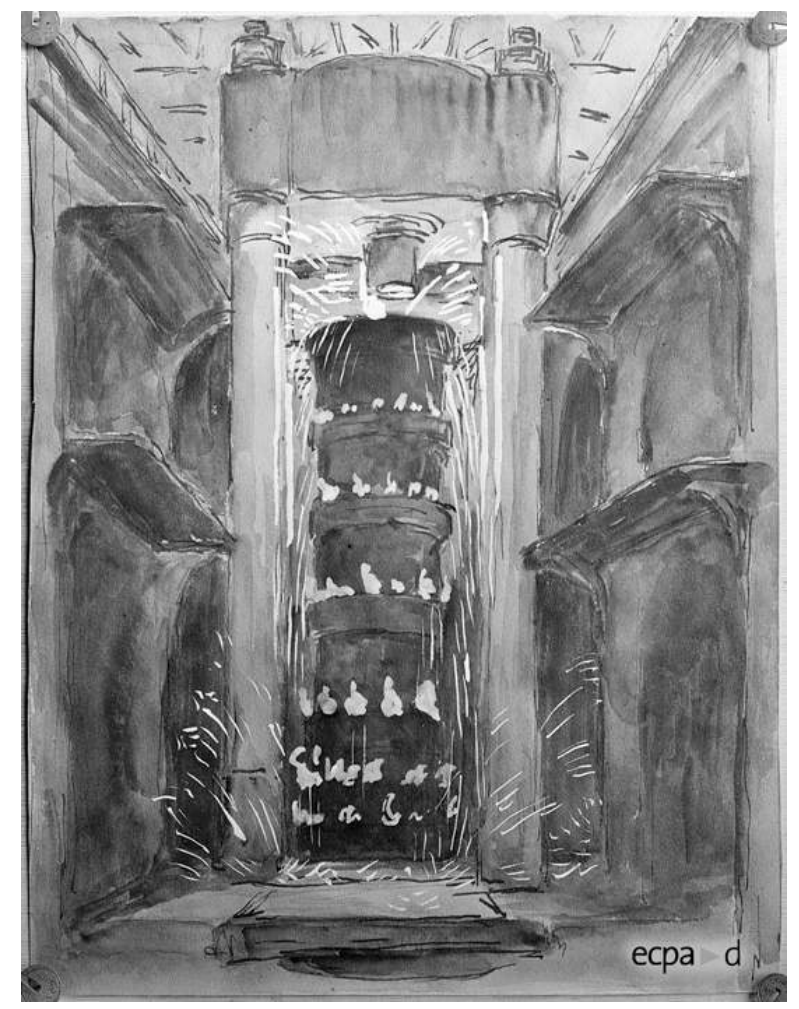

Auguste Bracquemond : la trempe d'un canon. Dessin préparatoire.

PHOT. QUESTE, PAUL. @ ECPAD, JUIN 1918, RÉF. SPA 151 в 7360.

$\mathrm{Au}$ cours de la Grande Guerre, les secteurs industriels déjà en pointe avant le conflit savent profiter de la période, malgré ou à cause de l'effort à consentir, pour moderniser la gestion de leur production. Fort de la pratique acquise dans l'usinage des munitions en très grand nombre, Louis Renault écrit en 1919: «Ces quatre années de guerre nous ont appris l'intérêt de l'organisation du travail, les méthodes qui permettent les fabrications les plus délicates sans main-d'œuvre spécialiste ». Ernest Mattern, directeur techniques des usines Peugeot pendant la guerre, déclarera plus tard : «C'est la fabrication des obus qui me montra ce qu'il était possible d'obtenir avec la fabrication en grande série». Les efforts de rationalisation effectués entre 1914 et 1918 aboutiront au début des années vingt à la généralisation de véritables chaînes intégrées dans le secteur de la construction mécanique. Dans l'aviation, après le creux observé immédiatement après l'armistice, la grande quantité d'appareils disponibles sur le marché permet un démarrage rapide du transport aérien civil, avec les premiers services de courrier au printemps 1919, puis de passagers à l'automne. L'expérience acquise dans les moteurs en étoile aboutit, dans l'entre-deux-guerres, à l'expérimentation au sein du Service technique de l'aéronautique de puissantes machines diesel d'aviation, avant l'invention des turbopropulseurs. En revanche, les industries plus traditionnelles telles que l'agro-alimentaire ou le cuir ne connaissent pas les mêmes avancées techniques et continuent à produire, tout au long du conflit, selon des méthodes encore assez artisanales.

Dans un environnement contraint par les pénuries de toutes sortes, notamment le manque de personnel et de matières premières, l'État et les industriels ont réussi à 
fonctionner pendant quatre années dans le cadre d'une véritable économie mixte, au sein de laquelle ils ont su nouer des partenariats efficaces.

\section{NOTES}

1. - L'Établissement de communication et de production audiovisuelle de la Défense est le successeur des Sections photographique et cinématographique de l'armée. Au cours du conflit et après l'armistice, les photographes et caméramans de cet organisme réalisent dans les territoires libérés des reportages qui témoignent des destructions opérées par l'ennemi. Sur la création et le fonctionnement des sections, voir, dans ce numéro, l'article de David SBRAVA. Entre inventaire et propagande: les destructions du patrimoine en Picardie au printemps 1917, vues par la Section photographique et cinématographique de l'armée (SPCA). Lien à insérer par l'éditeur.

2. - BITCHAKDJIAN, Jean. Charles Humbert, sénateur de la Meuse : presse, affaires, problèmes militaires sous la troisième république. Thèse d'histoire. Paris : université Paris-IV, 1988.

3. - PORTE, Rémy. "Mobilisation industrielle et guerre totale : 1916, année charnière ». Revue historique des armées, $\mathrm{n}^{\circ} 242,2006$, [en ligne], URL : http://rha.org/index4072.html (consulté le 19/03/2013).

4. - CARON, François. «L'embellie parisienne à la Belle Époque, l'invention d'un modèle de consommation ». Vingtième siècle. Revue d'Histoire, n 47 , juillet-septembre 1995, p. 43, [en ligne], URL : $\quad$ http://www.persee.fr/web/revues/home/prescript/article/ Xxs_0294-1759_1995_num_47_1_3179 (consulté le 25/03/2013).

5. - CARON, François. «L'embellie parisienne à la Belle Époque, l'invention d'un modèle de consommation ». Vingtième siècle. Revue d'Histoire, $\mathrm{n}^{\circ} 47$, juillet-septembre 1995, p. 43, [en ligne], URL : $\quad$ http://www.persee.fr/web/revues/home/prescript/article/ xxs_0294-1759_1995_num_47_1_3179 (consulté le 25/03/2013), p. 55.

6. - PORTE, Rémy. "Mobilisation industrielle et guerre totale : 1916, année charnière ». Revue historique des armées, $\mathrm{n}^{\circ} 242,2006$, [en ligne], URL : http://rha.org/index4072.html (consulté le 19/03/2013).

7. - NAKAJIMA, Toshikatsu. «L'impact de la guerre de 1914-1918 sur l'industrie mécanique de la région parisienne ». Histoire, économie \& société, 1993, vol. 12, p. 537-552, [en ligne], URL : http:// www.persee.fr/web/revues/home/prescript/article/hes_0752-5702_1993_num_12_4_1690 (consulté le 22/03/2013).

8. - Le groupe chapeauté par Renault comprend les entreprises suivantes : Brasier, Chenard et Walker, Clément-Bayard, Delage, Delahaye, Delaunay-Belleville, de Dion-Bouton, société de l'Éclairage électrique, Lorraine-Dietrich, Panhard et Levassor, Renault et Unic. HARDACH, Gerd. «La mobilisation industrielle en 1914-1918: production, planification et idéologie ». Dans: FRIDENSON, Patrick, BECKER, Jean-Jacques et BERSTEIN, Serge (dir.). «1914-1918: L'autre front ». Cahiers du Mouvement social n 2. Paris : Éditions Ouvrières, 1977, p. 92.

9. - Loi d'Albiez du 17 août 1915.

10. - Louis Renault en aurait eu l'idée après une visite au Creusot où le gouvernement l'avait envoyé pour étudier la question. Certains auteurs attribuent la paternité de l'idée à Étienne Clémentel, futur ministre du Commerce.

11. - Pour la fabrication des obus, voir MOULIN-BOURRET, Annie. Guerre et Industrie - ClermontFerrand 1912-1922 : la victoire du pneu, tome 1, Publications de l'Institut d'études du Massif central, 
p. 196, et COHEN, Yves. Organiser à l'aube du taylorisme : la pratique d'Ernest Mattern chez Peugeot, 1906-1919. Annales littéraires de l'université de Franche-Comté. Besançon : Presses universitaires franc-comtoises, 2001, p. 237.

12. - Film Des canons! Des munitions! L'artillerie de campagne (réf. 14.18 A 1040) et reportage photographique (réf. SPA $153 \mathrm{M})$. @ ECPAD.

13. - HUMBERT, Charles. Rapport sur la main-d'œuvre et l'outillage industriel, le matériel et les munitions d'artillerie et l'organisation du sous-secrétariat d'État à la Guerre (artillerie) (adopté le 7 juillet 1915). Réf. 69 S 113, [en ligne], URL: http://www.senat.fr/histoire/1914_1918/pdf/69\%20S\% 20Commissions\%20generales/Armee/Rapports/

FR_SENAT_069S_113/28_07-07-1915_HUMBERT.pdf (consulté le 7/05/2013).

14. - STRAUSS, Paul. Rapport fait à la commission de l'armée sur l'emploi de la main-d'œuvre féminine dans les usines de guerre (adopté le 20 novembre 1916). Réf. 69 S 120. [en ligne], URL: http:// www.senat.fr/histoire/1914_1918/pdf/69\%20S\%20Commissions\%20generales/Armee/Rapports/ FR_SENAT_069S_120/6_20-11-1916_STRAUSS.pdf (consulté le 10/06/2013).

15. - THÉBAUD, Françoise. "Les ouvrières dans les usines de guerre ». 14-18, le Magazine de la Grande Guerre, $\mathrm{n}^{\circ}$ 1, avril-mai 2001, p. 60.

16. - FELDMAN, Gérald D. «Les fondements politiques et sociaux de la mobilisation économique en Allemagne (1914-1916) ». Annales. Économies, Sociétés, Civilisations, 24 e année, nº 1, 1969, p. 122 et 123, [en ligne], URL: http://www.persee.fr/web/revues/home/prescript/article/ ahess_0395-2649_1969_num_24_1_422036 (consulté le 24/05/2013).

17. - MOULIN-BOURRET, Annie, op. cit., p. 514 et 516.

18. - HARDACH, Gerd, op. cit., p. 86.

19. - Les noms des caméramans demeurent en général inconnus avant février 1917. En effet, pour ce qui est des images animées tournées à une date antérieure, l'armée travaille en collaboration avec les compagnies de cinéma qui fournissent les premiers cadreurs et le matériel, effectuent les opérations de postproduction et gardent ensuite les rushes. En 1917, l'armée reprend totalement la main sur la réalisation des films militaires et l'on dispose à partir de février de données précises sur les tournages (lieux, dates, métrages de pellicule et noms des opérateurs).

20. - ROUSSEL, Yves. "L'histoire d'une politique des inventions (1887-1918)». Cahiers pour l'histoire du CNRS, (1989-3), p.39, [en ligne], URL: http://www.histcnrs.fr/pdf/cahiers-cnrs/ roussel-89.pdf (consulté le 16/04/2013).

21. - PORTE, Rémy, op. cit.

22. - Issue de la commission d'examen des inventions intéressant l'armée, créée après la guerre de 1870 .

23. - L'ensemble a brûlé en 1953.

24. - LEMAIRE, René, PECASTAINGTS, Pierre et HARTMAN, Gérard. «Produire en masse des moteurs d'aviation, 1914-1918 ». Dossiers historiques et techniques sur l'aéronautique française, 2008, [en ligne], URL: http://www.hydroretro.net/etudegh/ produire_en_masse_des_moteurs_d_aviation.pdf (consulté le 5/05/2013).

25. - ROUDIER, François. «Les moteurs d'avions dans la Grande Guerre " [document électronique]. CARLIER, Claude et PEDRONCINI, Guy. 1916 - L'émergence des armes nouvelles dans la Grande Guerre, actes du colloque organisé pour le $80^{\mathrm{e}}$ anniversaire de la bataille de Verdun, Hautes études militaires, 1997, URL: http://www.institut-strategie.fr/EAN_8.htm (consulté le 14/05/2013).

26. - Salmson possède également une usine à Moscou, détruite pendant la révolution.

27. - HARTMAN, Gérard. « Les moteurs Clerget». Dossiers historiques et techniques sur l'aéronautique française, 2003, [en ligne], URL: http://www.hydroretro.net/etudegh/clerget.pdf (consulté le 05/05/2013).

28. - À la fin de 1917, Hispano-Suiza crée un nouveau moteur de $300 \mathrm{ch}$, trop puissant pour la légèreté des appareils de l'époque et qui nécessite la mise au point d'avions plus robustes, comme 
le SEA 2, conçu par Marcel Dassault et Louis Potez mais qui ne sera pas mis en fabrication car la guerre se termine.

29. - MENIER, Gaston. Rapport sur l'état actuel de notre aviation militaire en appareils et en moteurs, par M. Gaston Menier (adopté le 7 avril 1917). Réf. 69S 122, [en ligne], URL: http://www.senat.fr/ histoire/1914_1918 (consulté le 07/05/2013).

30. - LEMAIRE, René, PECASTAINGTS, Pierre et HARTMAN, Gérard, op cit., p. 8.

31. - Toutefois, les constructeurs automobiles sont bien obligés de s'y mettre, tels Darracq, qui produit sous licence 2500 moteurs rotatifs Gnome et Rhône pendant le conflit.

32. - Les moteurs rotatifs ne peuvent dépasser 150 ou $200 \mathrm{ch}$. Pour aller au-delà, il faut une double étoile mais l'effet gyroscopique d'une telle masse en rotation devient problématique pour la gouverne de l'avion.

33. - CHADEAU, Emmanuel. "Stratégies d'entreprises et innovations internationales: les motoristes français d'aviation (1918-1940)». Histoire, économie et société, 1987, $6^{\mathrm{e}}$ année, $\mathrm{n}^{\circ} 2$, p. 264, [en ligne], URL: http://www.persee.fr/web/revues/home/prescript/article/ hes_0752-5702_1987_num_6_2_1449 (consulté le 07/05/2013).

34. - Réf. SPA 155 M 3139. (C ECPAD.

35. - NAKAJIMA, Toshikatsu, op. cit., p. 544.

36. - BIENFAIT, Jean. «L'industrie française de la machine-outil ». Revue de géographie de Lyon, vol. 36, no 1, 1961, p. 15, [en ligne], URL : http://www.persee.fr/web/revues/home/prescript/article/ geoca_0035-113x_1961_num_36_1_1700 (consulté le 15/05/2013).

37. - COHEN, Yves, op. cit., p. 230.

38. - STRAUSS, Paul, op. cit., p. 7.

39. - STRAUSS, Paul, op. cit., p. 18.

40. - Le chocolat fait partie des rations de réserve du soldat en campagne depuis une instruction du 4 février 1914 mais il ne doit pas y toucher. Celui qui est consommé parvient sur le front dans les colis envoyés par les familles.

41. - LLOSA, Marie. "La conserve alimentaire au service du soldat : une production de guerre ». Matériaux pour l'histoire de notre temps, 2008/3, nº 91, [en ligne], URL : http://www.cairn.info/ revue-materiaux-pour-l-histoire-de-notre-temps-2008-3-page-80.htm (consulté le 24/05/2013).

42. - HORNE, John. « Ouvriers, mouvements ouvriers et mobilisations industrielles ». Encyclopédie de la Grande Guerre, 1914-1918. Paris : Bayard, 2004, p. 607.

43. - Film Production intensive du matériel et des munitions. ( $1^{\text {re }}$ partie) (réf. 14.18 A 460) et film Fabrication de la grosse artillerie, usines de Saint-Chamond et du Creusot (réf. 14.18 A 1080). (C ECPAD.

\section{RÉSUMÉS}

Dès l'automne 1914, l'industrie française doit se réorganiser pour faire face à une guerre qui s'avère plus longue que prévu. Amputée de ses ressources en charbon et acier, elle s'efforce néanmoins d'approvisionner les tranchées en obus, nouveaux matériels et subsistances. La Section photographique et cinématographique de l'armée témoigne de l'effort collectif réalisé dans les nouvelles technologies militaires mais aussi dans les secteurs plus traditionnels.

From the Autumn of 1914, French industry had to undergo considerable reorganisation in order to respond to the demands of a war effort that was turning out longer that expected. Deprived of a large part of its raw materials of coal and steel, industry nevertheless succeeded in keeping the 
trenches supplied with shells, new military equipment and food. The images produced by the photographic and cinema section of the army bear witness to this collective effort in the field of new military technologies, but also in more traditional sectors.

INDEX

Mots-clés : industrie, armement, artillerie, construction mécanique, aviation, moteur, machineoutil, agro-alimentaire, photographie, cinéma

\section{AUTEUR}

\section{VÉRONIQUE GOLOUBINOFF}

Chargée d'études documentaires à l'Établissement de communication et de production audiovisuelle de la défense (ECPAD) - Fonds Première Guerre mondiale veronique.goloubinoff@ecpad.fr 